\title{
A parameterization of low visibilities for hazy days in the North China Plain
}

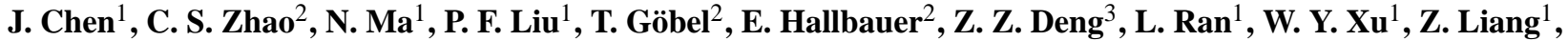 \\ H. J. Liu ${ }^{1}$, P. Yan ${ }^{4, *}$, X. J. Zhou ${ }^{1,4}$, and A. Wiedensohler ${ }^{2}$ \\ ${ }^{1}$ Department of Atmospheric and Oceanic Sciences, School of Physics, Peking University, Beijing, China \\ ${ }^{2}$ Leibniz Institute for Tropospheric Research, Leipzig, Germany \\ ${ }^{3}$ Key Laboratory of Middle Atmosphere and Global Environment Observation, Institute of Atmospheric Physics, Chinese \\ Academy of Sciences, Beijing, China \\ ${ }^{4}$ Chinese Academy of Meteorological Sciences, China Meteorological Administration, Beijing, China \\ * now at: Meteorological Observation Centre, China Meteorological Administration, Beijing, China
}

Correspondence to: C. S. Zhao (zcs@pku.edu.cn)

Received: 7 November 2011 - Published in Atmos. Chem. Phys. Discuss.: 30 November 2011

Revised: 16 May 2012 - Accepted: 20 May 2012 - Published: 6 June 2012

\begin{abstract}
Visibility degradation is a pervasive and urgent environmental problem in China. The occurrence of low visibility events is frequent in the North China Plain, where the aerosol loading is quite high and aerosols are strongly hygroscopic. A parameterization of light extinction $\left(K_{\mathrm{ex}}\right)$ for low visibilities on hazy days is proposed in this paper, based on visibility, relative humidity $(\mathrm{RH})$, aerosol hygroscopic growth factors and particle number size distributions measured during the Haze in China (HaChi) Project. Observational results show that a high aerosol volume concentration is responsible for low visibility at $\mathrm{RH}<90 \%$; while for $\mathrm{RH}$ $>90 \%$, decrease of visibility is mainly influenced by the increase of RH. The parameterization of $K_{\mathrm{ex}}$ is developed on the basis of aerosol volume concentrations and RH, taking into accounts the sensitivity of visibility to the two factors and the availability of corresponding data. The extinction coefficients calculated with the parameterization schemes agree well with the directly measured values.
\end{abstract}

\section{Introduction}

Visibility degradation is a pervasive environmental problem in China (Anderson et al., 2003; Quinn et al., 2003; Zhao et al., 2006b; Hoyle et al., 2009). Low visibility conditions present a host of problems of human activities such as air transport and highway traffic. In the North China
Plain (NCP), low visibility events are frequently encountered and mainly accompanied with haze as a result of either high aerosol loading or the strong hygroscopic growth of the aerosol particles.

Recently, China has undergone a rapid economic growth. Many regions have suffered from severe pollution caused by large concentrations of aerosol particles resulting from emissions from fossil fuel and biomass burning, transportation and some other combustion sources. High levels of particulate matter with the diameter smaller than $2.5 \mu \mathrm{m}\left(\mathrm{PM}_{2.5}\right)$ have been reported in a few megacities. Annual average (2005 2006) of $\mathrm{PM}_{2.5}$ in Beijing was $118.5 \pm 40.6 \mu \mathrm{g} \mathrm{m}^{-3}$ (Yang et al., 2011). It greatly exceeded the recently revised ambient air quality standard of China (GB3095-2012) for $\mathrm{PM}_{2.5}\left(35 \mu \mathrm{g} \mathrm{m}^{-3}\right.$, Grade II) and was at least 10 times those $\left(5 \sim 10 \mu \mathrm{g} \mathrm{m}^{-3}\right)$ measured in the eastern US (Hidy et al., 2009). The annual mean (2003 2007) visibility in Beijing was reported to fall between $10 \mathrm{~km}$ and $15 \mathrm{~km}$, with the mean value in summer reaching below $10 \mathrm{~km}$ (Zhang et al., 2010). Intensive aircraft observations in Beijing showed that the average aerosol number concentration near surface level (1419 $\mathrm{m}$ above the ground) was about $6600 \mathrm{~cm}^{-3}$, with the highest value over $10000 \mathrm{~cm}^{-3}$ (Zhao et al., 2006a; Deng et al., 2009; Liu et al., 2009). Remarkably high daily mean values, $150 \mathrm{~g} \mathrm{~m}^{-3}$ (Shen et al., 2009), of $\mathrm{PM}_{1}$ (particulate matter less than $1 \mu \mathrm{m}$ diameter) were reported in $\mathrm{Xi}$ 'an, one of the largest cities in northwest China from 1 
to 31 December 2006. At the Longfengshan site $\left(127^{\circ} 36^{\prime} \mathrm{E}\right.$, $44^{\circ} 44^{\prime} \mathrm{N}, 331 \mathrm{~m}$ a.s.1.), a regional atmospheric background station of northeast China, a daily mean horizontal visibility and $\mathrm{PM}_{10}$ (particulate matter less than $10 \mu \mathrm{m}$ diameter) concentration of $11 \mathrm{~km}$ and $70 \mu \mathrm{g} \mathrm{m}^{-3}$ was reported for a typical hazy day in 2008 (Wang et al., 2010).

Hygroscopicity greatly affects aerosol optical properties (Covert et al., 1972; Cheng et al., 2008a; Stock et al., 2011). Hygroscopic growth increases aerosol extinction coefficients by enlarging particles by the uptake of liquid water. On the other hand, hygroscopic growth decreases aerosol extinction by lowering the refractive index, since the water that is taken up has a smaller refractive index compared to other aerosol components. The positive effect of the aerosol size on aerosol extinction coefficients outweighs the negative effect of the refractive index, leading to an increase in aerosol extinction and a significant degradation in visibility, as has been observed in some field campaigns (Yan et al., 2008a; Pan et al., 2009). Measurements of ambient aerosol hygroscopic properties were conducted in the NCP using a Hygroscopicity Tandem Differential Mobility Analyser (H-TDMA) (Swietlicki et al., 2008). Corresponding observational results of the Haze in China Project (HaChi) presented that average hygroscopic growth factor of more hygroscopic particles (initial diameters of $100 \mathrm{~nm}$ ) was about $2.45 \pm 0.07$ at $98.5 \%$ relative humidity (RH) (Liu et al., 2011). This value was 0.25 lower than that of the pure ammonium sulphate particles, indicating high hygroscopicity of the ambient aerosols.

Studies regarding the trends of visibility (Deng et al., 2008; Chang et al., 2009), source apportionment of visibility impairment (Ying et al., 2004) and the correlation between visibility and its influencing factors have shown that visibility was largely influenced by the particle size distribution (Motallebi, et al., 1990; Cheng et al., 2008b), meteorological conditions (Wu et al., 2005; Deng et al., 2008; Zhang et al., 2010) and aerosol chemical components (Randles, et al., 2004; Armin Sorooshian, et al., 2008; Wen et al., 2010). An exponential correlation has been found between visibility and aerosol mass concentration (Wen et al., 2010). It has also been reported that the mixing state of black carbon (BC, i.e. soot particles) has an important effect on visibility by changing aerosol optical properties (Yu et al., 2010; Ma et al., 2012).

For dry particles with fixed size distribution, light extinction is directly related to the aerosol mass loading. The second important parameter that controls light extinction is aerosol size distribution, followed by aerosol refractive index, particle shape and density. Under ambient conditions, RH has a marked effect on light extinction through hygroscopic growth of particles, which is a key factor in visibility degradation. It is thereby of great importance to understand the correlation between low visibility, aerosol loading, size distribution, as well as aerosol hygroscopic growth.

Due to frequent haze events in China, visibility is often seriously impaired (Wu et al., 2005), exerting hazardous in- fluences on both road traffic and air transport. However, studies on visibility and its relationship with aerosol hygroscopic properties are still rather limited in China, due to the lack of aerosol hygroscopic properties measurements. In order to increase the efficiency and safety of transportation under lowvisibility conditions, efforts aimed at developing a parameterization of low visibilities on hazy days are necessary for low visibility forecasts and numerical simulations. In this paper, a parameterization of low visibilities for hazy days has been proposed.

This work is based on the analysis of in-situ measurements of visibility, $\mathrm{RH}$, particle number size distribution (PNSD) and inferred size-resolved hygroscopic growth factors at subsaturated conditions $(\mathrm{RH}<100 \%)$ during the HaChi summer campaign. The characteristics of aerosol number, volume concentrations, $\mathrm{RH}$ and visibility are displayed in Sect. 4.1. In Sect. 4.2, results from a comparison study between the Mie Model calculated and measured extinction coefficients $\left(K_{\mathrm{ex}}\right)$ are shown. The theoretical calculation of $K_{\mathrm{ex}}$, as well as the dependence of $K_{\mathrm{ex}}$ on aerosol volume concentration, PNSD pattern and RH are discussed in Sect.4.3. Finally, a parameterization of low visibilities under hazy conditions is presented in Sect. 4.4.

\section{Measurement}

\subsection{Site description}

The HaChi summer campaign was carried out at the Wuqing Meteorological Station $\left(39^{\circ} 23^{\prime} \mathrm{N}, 117^{\circ} 01^{\prime} \mathrm{E}, 7.4 \mathrm{~m}\right.$ a.s.l.), northwest of the Wuqing town. Wuqing is a suburban district of Tianjin (with about 0.8 million inhabitants) and located among a cluster of cities. The Wuqing town is about $80 \mathrm{~km}$ to the southeast of the megacity Beijing and $30 \mathrm{~km}$ to the northwest of the megacity Tianjin. The area surrounding the site is in agricultural, residential and industrial land use. Most of the neighboring factories are clustered to east of the site, while a large tract of farmland is situated to the west and south of Wuqing, with railways and busy roads running through. Wuqing is highly representative of regional aerosol pollution in the NCP and is an ideal place for our study.

\subsection{Instruments and data processing}

The HaChi summer campaign took place from 13 July to 14 August 2009. Ground-level aerosol particle number size distribution (PNSD), hygroscopicity, chemical composition (Liu et al., 2011), optical properties, visibility and RH were measured during the entire field campaign.

A combined system of Twin Differential Mobility Particle Sizer (TDMPS, Leibniz-Institute for Tropospheric Research (I $f$ T), Germany; Birmili et al., 1999) and Aerodynamic Particle Sizer (APS, TSI Inc., Model 3320) is used to monitor the PNSDs ranging from $3 \mathrm{~nm}$ to $10 \mu \mathrm{m}$ under dry condition $(\mathrm{RH}<30 \%)$ every $10 \mathrm{~min}$. PNSDs with 
electrical mobility diameters ranging from 3 to $800 \mathrm{~nm}$ were measured by TDMPS. PNSDs with aerodynamic diameters ranging from $500 \mathrm{~nm}$ to $10 \mu \mathrm{m}$ were measured by APS. More information about the two instruments is in Ma's study on aerosol optical properties in the NCP (Ma et al., 2011).

The High Humidity Tandem Differential Mobility Analyser (HH-TDMA) was applied to measure the size-resolved hygroscopic growth factors of the ambient aerosols (initial diameters, $\mathrm{D}_{p}$, are 50,100, 200 and $250 \mathrm{~nm}$ ) at $90 \%, 95 \%$ and $98.5 \%$ RH (Hennig et al., 2005). More details of the instrument and observational aerosol hygroscopic properties are described in Liu et al. (2011).

Visibility was monitored with a forward scattering measuring visibility meter (Model FD 12, Vaisala Corporation, Finland). The Vaisala FD12 visibility meter transmits infrared (IR) light pulses at a peak wavelength of $875 \mathrm{~nm}$, and detects the amount of light scattered by a small measurement volume at an angle of about $33^{\circ}$. The reason for choosing this forward scattering angle is that the differences among the scattering phase functions of particles at different sizes are minimized. The detected optical signal, which varies linearly with the visibility, is firstly converted into a frequency and finally converted to visibility by proprietary algorithms, based on extensive calibration against a well calibrated Vaisala's MITRAS transmissometer (Wauben, 2011). Briefly, the amount of scattering measured in this way is empirically linked to the extinction coefficient, taking into consideration of the relationship between the amount of forward scattering and the extinction of the scattering medium.

There is great difference between visibility and visual range (VR), and the latter one is a more rigorously defined concept. The visual range is a function of the atmospheric extinction coefficient, the albedo and visual angle of the target, and the observer's threshold contrast at the moment of observation. In the daytime, the visual range can be expressed as the formula in Eq. (1) (Middleton, 1952; Johnson, 1954).

$\mathrm{VR}=\frac{1}{K_{\mathrm{ex}}} \ln \frac{|C|}{\varepsilon}$

where there is a contrast $C$ between the horizon target and its background viewed through an atmosphere of extinction coefficient $K_{\text {ex }}$ by an observer whose momentary threshold contrast is $\varepsilon$.

In practical calculation of visibility, an important application of this formula is to the case of a black target (for which $C=1$ ), and the threshold contrast $\varepsilon$ is also assigned a constant value. Hence, the correlation between the visibility (VIS) and $K_{\text {ex }}$ can be expressed into the following empirical Eq. (2) (FD12P User Guide in English) provided by the Vaisala Visibility Meter User's Guide, which is basically derived from the Koschmieder relation (Griffing, 1980; Husar et al., 2000; Carrico et al., 2003):

$$
K_{\mathrm{ex}}\left(\mathrm{km}^{-1}\right)=\frac{3}{\operatorname{VIS}(\mathrm{km})}
$$

Undoubtedly, there is certain error in the measured extinction coefficient (reported of no less than $10 \%$ by Crosby, 2003), since light absorbing has not been measured but presumed with an empirical constant single scattering albedo.

In this study, instantaneous visibilities at a temporal resolution of $15 \mathrm{~s}$ are further averaged into 10-min averages. The measured extinction coefficient can thus be calculated from monitored visibility according to Eq. (2).

To match the ten-minute PNSDs data, one-minute meteorological parameters were also averaged into ten-minute averages when the missing data in the ten-minute interval less than $40 \%$ of those that should be observed in the corresponding ten minutes. Since we focused on low visibility during hazy days, all data during $0-12 \mathrm{~h}$ on 11 August, when a heavy fog event occurred, were excluded from the dataset.

\section{Methodology for $K_{\text {ex }}$ calculation}

In this section, a brief introduction to $K_{\text {ex }}$ calculation is presented. $K_{\mathrm{ex}}$ at different RHs and aerosol volume concentrations can be theoretically obtained by using averaged PNSD and the Mie Model, in which aerosol hygroscopic growth has been taken into account. Size-resolved hygroscopic growth factors are determined by using a combination of a fourmode PNSD fitting and HHTDMA-measured hygroscopicity parameter $\kappa$ at four specific particle sizes. Then follows the size-resolved refractive indices need to be considered in the Mie Model. Section 3.3 is a brief introduction to the Mie Model.

\subsection{Size-resolved hygroscopic growth factors $\left(f\left(\mathbf{D}_{p}, \mathbf{R H}\right)\right)$}

High aerosol hygroscopicity would greatly degrade visibility due to increasing light extinction of growing particles. The hygroscopic growth factor $\left(f\left(\mathrm{D}_{p}, \mathrm{RH}\right)\right)$ is often adopted to describe aerosol hygroscopicity and defined as a function of RH:

$$
f\left(D_{\mathrm{p}}, \mathrm{RH}\right)=\mathrm{D}_{p}(\mathrm{RH}) / \mathrm{D}_{p, \text { dry }}
$$

where $D_{\mathrm{p}}(\mathrm{RH})$ and $D_{p \text {, dry }}$ are particle diameters under humid and dry conditions, respectively.

Size-resolved hygroscopic growth factors for aerosols within the range of $3 \mathrm{~nm} \sim 10 \mu \mathrm{m}$ were obtained from the measured PNSDs and HHTDMA-determined hygroscopicity parameter $\kappa$ during the summer campaign. Firstly, the measured PNSDs were fitted with four lognormal modes (Whitby, 1978; Birmili et al., 2001; Hussein et al., 2005; Nowak, 2005), a nucleation mode with geometric mean diameters between 3 and $25 \mathrm{~nm}$, an Aitken mode with geometric mean diameters between 25 and $100 \mathrm{~nm}$, an accumulation mode with geometric mean diameters between $100 \mathrm{~nm}$ and $1 \mu \mathrm{m}$, and a coarse mode with geometric mean diameters between 1 and $5 \mu \mathrm{m}$. This modified four-mode PNSD fitting 
method differs from traditional fitting methods for submicron particles, where only a fixed PNSD pattern and a closure of aerosol number concentration between the original and reconstructed PNSDs are needed. The modified method can also be applied to the parameterization of supermicron particles. The optimal fitting results are supposed to meet the requirements that it can not only reconstruct the particle number size distribution, but also the aerosol surface area and volume distributions. In other words, the closures of aerosol number, surface area and volume concentrations could be achieved between the reconstructed PNSDs and the measured ones.

Based on the assumption that aerosols in a specific mode have common sources or have experienced similar aging processes, the corresponding hygroscopicity parameter $\kappa$ in one mode should be the same due to the same chemical compositions. Hence, the HHTDMA-measured hygroscopicity parameter $\kappa$ of particles with diameters of $50 \mathrm{~nm}, 100 \mathrm{~nm}$, $200 \mathrm{~nm}$ and $250 \mathrm{~nm}$ can be used to deduce the corresponding $\kappa$ for each of the four modes of the reconstructed PNSDs. Considering the primary chemical composition in the coarse mode is nearly hydrophobic, the $\kappa$ for this mode is assumed to be 0 . Consequently, with the corresponding contribution of each mode to the $\kappa$ of a specific particle size, the mean sizeresolved $\kappa$ for aerosols with diameters in the range of $3 \mathrm{~nm}$ $\sim 10 \mu \mathrm{m}$ can be estimated from the known $\kappa$ of each mode.

$\kappa\left(D_{\mathrm{p}}\right)=\frac{\sum_{i=1}^{4} \kappa_{\mathrm{i}} \cdot N_{\mathrm{i}}\left(D_{\mathrm{p}}\right)}{\sum_{i=1}^{4} N_{\mathrm{i}}\left(D_{\mathrm{p}}\right)}$

Where $\kappa_{\mathrm{i}}$ represents the $\kappa$ of the $i$ mode, $N_{\mathrm{i}}\left(D_{\mathrm{p}}\right)$ stands for the number concentration of dry particles (with diameter of $D_{\mathrm{p}}$ ) in the $i$ mode.

Accordingly, the size-resolved hygroscopic growth factors at different RHs can be derived from the size-resolved $\kappa$ using following equation in Petters et al. (2007):

$\mathrm{RH}=\frac{f^{3}-1}{f^{3}-(1-\kappa)} \cdot \exp \left(\frac{4 \sigma_{s / a} \cdot M_{\mathrm{w}}}{R \cdot T \cdot D_{\mathrm{p}} \cdot f}\right)$

where $\sigma_{s / a}$ is the surface tension of the solution/air interface, $M_{\mathrm{w}}$ is the molecular weight of water, $R$ is the universal gas constant, $T$ is temperature, $D_{\mathrm{p}}$ is the dry particle diameter, and $f$ is the aerosol hygroscopic growth factor.

Figure 1 displays the averaged size-resolved hygroscopic growth factors at $80 \%, 90 \%, 95 \%, 98.5 \%$ and $99 \% \mathrm{RH}$. Mean values of HHTDMA-measured hygroscopic growth factors (with dry diameters of $50 \mathrm{~nm}, 100 \mathrm{~nm}, 200 \mathrm{~nm}$ and $250 \mathrm{~nm}$ ) at RHs of $90 \%, 95 \%$ and $98.5 \%$ were shown in colored circles; error bars stand for the standard deviation (Liu et al., 2011). It can be clearly seen that the hygroscopic growth factors of particles with diameters between $50 \mathrm{~nm}$ and $1 \mu \mathrm{m}$ are all higher than 1.25 at $80 \% \mathrm{RH}$, significantly higher than that of the other sizes. The hygroscopic



Fig. 1. Size-resolved hygroscopic growth factors at $80 \%, 90 \%$, $95 \%, 98.5 \%$ and $99 \%$ RH (displayed in colored lines). Colored circles represent the corresponding mean values of measured hygroscopic growth factors of particles (with dry diameters of $50 \mathrm{~nm}$, $100 \mathrm{~nm}, 200 \mathrm{~nm}$ and $250 \mathrm{~nm})$ at set RHs $(90 \%, 95 \%$ and $98.5 \%$, respectively) during HaChi summer campaign; the error bars represent \pm 1 standard deviation (Liu et al., 2011).

growth factors of particles larger than $2 \mu \mathrm{m}$ are exclusively close to 1.0, given the principal chemical compositions in coarse mode are assumed to be hydrophobic mineral dust. Differences of hygroscopic growth factors for different particle sizes are larger when the RH level is higher. The hygroscopic growth factor of particles in a range of $200 \mathrm{~nm}$ to $1 \mu \mathrm{m}$ is higher than 1.5 at $90 \% \mathrm{RH}$, and nearly 2.0 at $95 \%$ $\mathrm{RH}$. The hygroscopic growth factors of particles within the range of $50 \mathrm{~nm} \sim 1 \mu \mathrm{m}$ are exclusively higher than 2.0 when $\mathrm{RH}=99 \%$, and those of particles ranging from $250 \mathrm{~nm}$ to $1 \mu \mathrm{m}$ even exceed 3.0. It indicates high aerosol hygroscopicity in the NCP, which has been supported by HHTDMA measurements during the HaChi campaign. Averaged hygroscopic growth factor of more hygroscopic particles with dry diameter of $100 \mathrm{~nm}$ was reported as $2.45 \pm 0.07$ at $98.5 \%$ $\mathrm{RH}$ in Liu et al. (2011). This value is comparable to that of $f=2.75$ at $100 \mathrm{~nm}$ and $98.5 \% \mathrm{RH}$ for pure ammonium sulphate particles.

Hygroscopic growth of aerosols leads to a change in particle size distribution. To obtain the PNSDs under ambient relative humidity conditions (ambient RH PNSDs), we can use the PNSDs measured under dry conditions and the mean size-resolved hygroscopic growth factors.

\subsection{Size-resolved refractive indices $\left(\tilde{m}\left(D_{p}, \mathbf{R H}\right)\right)$}

Size-resolved refractive indices are key factors in accurately calculating extinction coefficients with the Mie model. A two-component optical aerosol model of light-absorbing $\mathrm{BC}$ and non-light-absorbing components (Wex et al., 2002; 
Cheng et al., 2006) is used for determining the refractive index for dry particles $\left(\tilde{m}_{p}\right)$. In this paper, dry particle is assumed to be a completely internal mixture of $\mathrm{BC}$. The refractive index for dry particles is derived as a volume-weighted average between $\mathrm{BC}$ and non-light-absorbing components:

$\tilde{m}_{p}=f_{\mathrm{BC}, \mathrm{V}} \cdot \tilde{m}_{\mathrm{BC}}+\left(1-f_{\mathrm{BC}, \mathrm{V}}\right) \cdot \tilde{m}_{\mathrm{non}}$

where $\tilde{m}_{\mathrm{BC}}$ and $\tilde{m}_{\text {non }}$ are the refractive indices respectively for $\mathrm{BC}$ and non-absorbing component, which are set to be 1.96-0.66 $i$ (Seinfeld and Pandis, 1998) and $1.53-10^{-7} i$ (Wex et al., 2002). $f_{\mathrm{BC}, \mathrm{V}}$ stands for the volume fraction of $\mathrm{BC}$ and can be expressed as:

$f_{\mathrm{BC}, \mathrm{V}}=\frac{m_{\mathrm{BC}}}{\rho_{\mathrm{BC}} \cdot \mathrm{V}_{\mathrm{PNSD}}}$

where $\mathrm{V}_{\mathrm{PNSD}}$ is the corresponding aerosol volume concentration of each measured PNSD during the HaChi campaigns. $m_{\mathrm{BC}}$ represents the total mass concentration of $\mathrm{BC}$, and $\rho_{\mathrm{BC}}$ is the density of $\mathrm{BC}$. The total mass concentration of $\mathrm{BC}$ is obtained from measurements during the HaChi campaigns in spring and summer 2009 at Wuqing. Based on the reported BC-density range of $1.00 \sim 2.00 \mathrm{~g} \mathrm{~cm}^{-3}$ (Ouimette and Flagan, 1982; Sloane et al., 1983, 1984; Seinfeld and Pandis, 1998), an average value of $1.5 \mathrm{~g} \mathrm{~cm}^{-3}$ (Ma et al., 2011) is adopted. The volume fractions of $\mathrm{BC}$ and the corresponding refractive indices for dry particles can be calculated using Eqs. (7) and (6).

Our results show that the mean refractive indices for dry particles are 1.558-0.043 $i$ for spring 2009 and 1.562-0.049 $i$ for summer 2009. Their corresponding standard deviations in the two seasons were $0.009-0.014 i$ and $0.010-0.016 i$, respectively. It indicates that in situ observational refractive indices for dry particles slightly vary with the volume fractions of BC. Possible influences of different refractive indices of dry particles on extinction coefficients are also discussed using the mean PNSD with the Mie Model. The average percentage deviations of aerosol extinction coefficients, namely, the ratios between the standard deviations and mean values of calculated extinction coefficients during the two campaigns, are typically less than $3 \%$ (for spring) and $1 \%$ (for summer). This is consistent with the results of Lesins et al. (2002). The mean value of the refractive indices during the two seasons is thereby taken as the refractive index for dry particles, with $\tilde{m}_{p}=1.56-0.045 i$.

Under conditions of high humidity, water taken up, i.e., adsorbed, by hygroscopic compounds in the aerosol must be taken into consideration for refractive indices. The sizeresolved refractive index for internally mixed aerosols is derived as a simple volume-weighted average between the refractive indices of dry particles and water component. The refractive index for pure water is $\tilde{m}_{\mathrm{w}}=1.33-0 i$. The volume of ambient PNSDs ( $\left.\mathrm{V}_{\mathrm{PNSD}, \mathrm{RH}}\right)$ in each size bin can be derived from dry PNSDs by considering aerosol hygroscopic growth. The size-resolved volume of water taken up $\left(\mathrm{V}_{\mathrm{w}}\right)$ can be equivalently expressed as the difference of volumes $\left(\mathrm{V}_{\mathrm{PNSD}, \mathrm{RH}}-\mathrm{V}_{\mathrm{PNSD} \text {,dry }}\right)$ between ambient and dry PNSDs ( $\left.\mathrm{V}_{\mathrm{PNSD} \text {,dry }}\right)$ in each size bin. The size-resolved volume fraction of water content $\left(f\left(\log D_{\mathrm{p}}\right)_{\mathrm{w}, \mathrm{V}}\right)$ is defined as $f\left(\log D_{\mathrm{p}}\right)_{\mathrm{w}, \mathrm{V}}=\mathrm{V}_{\mathrm{w}} / \mathrm{V}_{\mathrm{PNSD}, \mathrm{RH}}$. Similarly, the size-resolved refractive index $\left(\tilde{m}\left(\mathrm{D}_{p}, \mathrm{RH}\right)\right)$ can be expressed as a volumeweighted average between the two components:

$\tilde{m}\left(D_{\mathrm{p}}, \mathrm{RH}\right)=\left(1-f\left(\log D_{\mathrm{p}}\right)_{\mathrm{w}, \mathrm{V}}\right) \cdot \tilde{m}_{p}+f\left(\log D_{\mathrm{p}}\right)_{\mathrm{w}, \mathrm{V}} \cdot \tilde{m}_{\mathrm{W}}$

\subsection{Mie model}

The Mie Model is employed to calculate major optical parameters of a spherical particle, such as scattering, absorption and extinction cross sections $\left(\sigma_{\mathrm{sp}}, \sigma_{\mathrm{ap}}, \sigma_{\mathrm{ex}}\right)$ and scattering phase function $\left(P_{\theta}\right)$. Calculations in the Mie model are based on the Mie theory (Mie et al., 1908). Key parameters can be determined by particle size parameter $x$ and the complex reflective index $\tilde{m}$ following the Bohren-Huffman Mie model (BHMIE) (Bohren and Huffman, 1983).

$x=\pi D_{\mathrm{p}} / \lambda$

$\tilde{m}=n_{\mathrm{r}}+n_{\mathrm{i}}$

Where $D_{\mathrm{p}}$ is the particle diameter, and $\lambda$ represents the wavelength of incident light. $n_{\mathrm{r}}$ and $n_{\mathrm{i}}$ are the real and imaginary part of the reflective index, representative of the scattering and absorption item, respectively. They are wavelengthdependent and nonnegative.

Based on size-resolved hygroscopic growth factors provided in Sect. 3.1 and size-resolved refractive indices in Sect. 3.2, the $K_{\text {ex }}$ for each size bin can be calculated by using the BHMIE Model at a given RH in the subsaturated ambient atmosphere. Total $K_{\mathrm{ex}}$ of the PNSDs is derived by using the aerosol number concentration at each size bin, which is constant before and after hygroscopic growth. The integration limits of the aerosol diameter are $3 \mathrm{~nm} \sim 10 \mu \mathrm{m}$ in this paper.

$K_{\mathrm{ex}}=\int_{3 \mathrm{~nm}}^{10 \mu \mathrm{m}} \sigma_{\mathrm{ex}}\left(D_{\mathrm{p}}\right) n\left(\log D_{\mathrm{p}}\right) d \log D_{\mathrm{p}}=\sum_{D_{\mathrm{p}}=3 \mathrm{~nm}}^{10 \mu \mathrm{m}} \sigma_{\mathrm{ex}}\left(D_{\mathrm{p}}\right) \cdot d N$

\section{Results and discussion}

\subsection{Characteristics of visibility, aerosol number concentration, volume concentration and $\mathrm{RH}$}

The occurrence frequencies (Freq, in \%) of five specific visibility ranges are shown in Table 1 . The frequency of VIS $<10 \mathrm{~km}$ reaches up to $89.5 \%$. The frequencies of VIS $<3 \mathrm{~km}$ and VIS $<1 \mathrm{~km}$ exceed $50 \%$ and $10 \%$, respectively. During the valid 24-day observational period $470 \mathrm{~h}$ in total experienced a low visibility (VIS $<10 \mathrm{~km}$ ). On average, visibilities below $3 \mathrm{~km}$ occurred for more than $10 \mathrm{~h}$ each day. It was evident that the NCP frequently suffered from severe low visibility events. 
Table 1. Frequencies (Freq) of different visibility ranges.

\begin{tabular}{ll}
\hline VIS $(\mathrm{km})$ & Freq $(\%)$ \\
\hline$<1$ & 13 \\
$1 \sim 3$ & 41.5 \\
$3 \sim 5$ & 19.2 \\
$5 \sim 10$ & 15.8 \\
$>10$ & 10.5 \\
\hline
\end{tabular}

The statistical results of visibility (VIS), aerosol number $(N)$, surface (S) and volume (V) concentrations, as well as the effective radius $\left(R_{\text {eff }}\right)$ and RH in the NCP are given in Table 2. As can be seen from the corresponding minimum (Min), 5th percentile (5\%), 95th percentile (95\%) and maximum (Max) values, all of the parameters show a wide range. The average visibility is only $4.15 \mathrm{~km}$, with the lowest value of about $21 \mathrm{~m}$. The median values of the PNSD parameters are all slightly lower than mean values. The 5th and 95th percentiles of aerosol number concentrations are $8.96 \times 10^{3}$ and $2.74 \times 10^{4} \mathrm{~cm}^{-3}$, with the average level exceeding $1.7 \times 10^{4} \mathrm{~cm}^{-3}$. While the mean value of particles larger than $100 \mathrm{~nm}$ is even higher than $5300 \mathrm{~cm}^{-3}$, indicating heavy aerosol pollution in the NCP. The high aerosol surface and volume concentrations also confirm the aerosol polluted status. This has also been demonstrated by Ma et al. (2011), in which high average scattering coefficients $\left(\sigma_{\mathrm{sp}, 550 \mathrm{~nm}}\right)$ of $874 \pm 282 \mathrm{Mm}^{-1}$ were observed during two heavily polluted episodes in 2009 summer. The effective aerosol radii were mainly distributed in the range of $105 \sim 437 \mathrm{~nm}$, with a mean value of $192 \mathrm{~nm}$. Observed RH varied from $28 \%$ to $100 \%$, with a high average value of $81.6 \%$. Humid weather conditions are common in the NCP during summertime.

Aerosol number concentration is not directly related empirically or theoretically to extinction or scattering unless limited to the optical subrange of diameters. Therefore, the aerosol number concentration is not an effective representative of visibility degradation. To gain more insight into correlations between low visibility and its influencing factors, $\mathrm{RH}$ and aerosol volume concentration were avaraged into bins. RH was divided into 7 bins, with $\mathrm{RH}<40 \%$ as a single bin and RH from $40 \%$ to $100 \%$ being divided into bins of $10 \%$ interval. Calculated aerosol volume concentrations were divided into 20 even bins, with the concentrations ranging from $0 \sim 250 \mu \mathrm{m}^{3} \mathrm{~cm}^{-3}$. Visibility data were also sorted according to the bins of above parameters. The occurrence frequency of the visibility for each bin was calculated for five ranges (VIS $\geq 10 \mathrm{~km}, 5 \mathrm{~km} \leq \mathrm{VIS}<10 \mathrm{~km}, 3 \mathrm{~km} \leq \mathrm{VIS}<5 \mathrm{~km}$, $1 \mathrm{~km} \leq \mathrm{VIS}<3 \mathrm{~km}$ and VIS $<1 \mathrm{~km}$ ). The stacked colored bars in Fig. 2 show percentages of five specific visibility groups for different ranges of aerosol volume concentration and RH. The frequency distribution (FD) of aerosol volume concentration and RH were calculated and displayed in dotted dark lines.
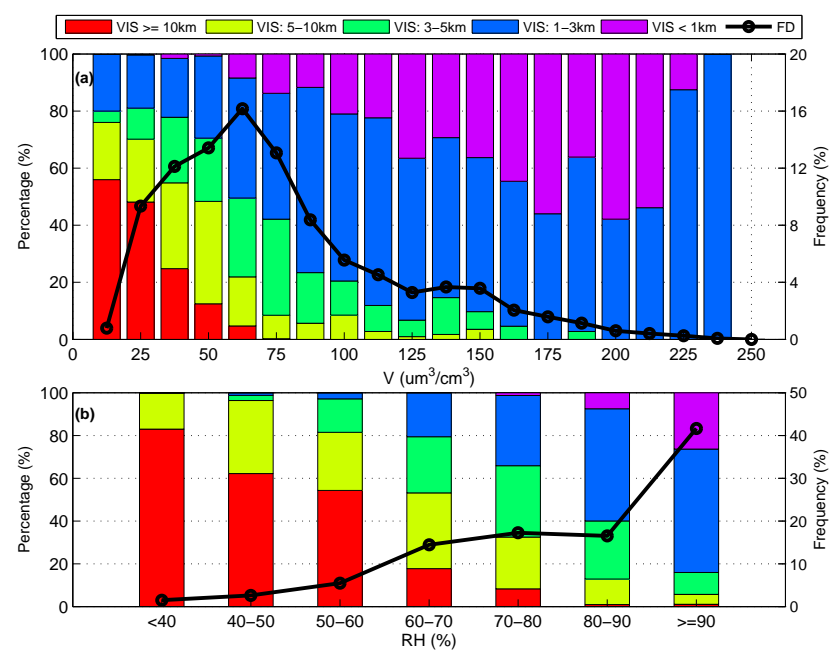

Fig. 2. Percentages of five specific visibility groups at different aerosol (a) volume concentration $(V)$ and corresponding (b) $\mathrm{RH}$ ranges, as well as their corresponding frequency distribution (FD) presented in dotted dark lines; the colored bars stand for the situation of corresponding visibility groups (VIS $>=10 \mathrm{~km}, 5 \mathrm{~km}$ $=<$ VIS $<10 \mathrm{~km} 3 \mathrm{~km}=<$ VIS $<5 \mathrm{~km}, 1 \mathrm{~km}=<$ VIS $<3 \mathrm{~km}$ and VIS $<1 \mathrm{~km})$.

Apparently, the percentages of the five visibility groups increase sharply with growing aerosol volume concentrations and RH. For aerosol volume concentrations higher than $75 \mu \mathrm{m}^{3} \mathrm{~cm}^{-3}$ or RH exceeding $90 \%$, over $90 \%$ of the visibilities are below $5 \mathrm{~km}$. When aerosol volume concentrations are higher than $100 \mathrm{\mu m}^{3} \mathrm{~cm}^{-3}$ or RH $>90 \%$, about $85 \%$ of the visibilities are below $3 \mathrm{~km}$. This is in accordance with the statistical results of the highly frequent low visibility events in Table 1 . The occurrence probability of RH $\geq 90 \%$ is higher than $40 \%$ (Fig. 2b), while the probability of high aerosol volume concentration over $100 \mu^{3} \mathrm{~cm}^{-3}$ is no more than $20 \%$ (Fig. 2a). Aerosol volume concentration of about $60 \mu \mathrm{m}^{3} \mathrm{~cm}^{-3}$ has the highest probability of occurrence and is regarded here as the average pollution level in the NCP. Because a high RH is more frequently observed than high volume concentrations, it should be considered to be the more critical influencing factor of low visibility in this region.

Figure 2 also reaveals that VIS $<3 \mathrm{~km}$ and VIS $<1 \mathrm{~km}$ can occur at RHs $<50 \%$ and $<80 \%$, respectively. The visibility degradation at relatively low RH results from severe aerosol pollution. At lower aerosol volume concentrations on the other hand, aerosol hygroscopic growth at high RH has the key effect on visibility reduction. Most of the extremely low visibility events (VIS $<1 \mathrm{~km}$ ) in the NCP are encountered due to the concurrence of heavy aerosol pollution and strong RH, which leads to the occurrence of haze. 
Table 2. Characteristics of VIS, $N, \mathrm{~S}, \mathrm{~V}, R_{\text {eff }}$ and RH.

\begin{tabular}{llllllll}
\hline Parameter & Min & $5 \%$ & Median & Mean & $95 \%$ & Max & Std \\
\hline VIS $(\mathrm{km})$ & 0.021 & 0.674 & 2.63 & 4.15 & 13.1 & 33.0 & 4.04 \\
$N\left(10^{3} \mathrm{~cm}^{-3}\right)$ & 3.35 & 8.96 & 16.7 & 17.2 & 27.4 & 51.1 & 5.91 \\
$N_{100}^{*}\left(10^{3} \mathrm{~cm}^{-3}\right)$ & 0.500 & 1.99 & 4.91 & 5.32 & 10.5 & 15.7 & 2.55 \\
$\mathrm{~S}\left(10^{2} \mu \mathrm{m}^{2} \mathrm{~cm}^{-3}\right)$ & 0.945 & 3.76 & 9.57 & 10.7 & 21.3 & 30.5 & 5.48 \\
$\mathrm{~V}\left(10^{2} \mu \mathrm{m}^{3} \mathrm{~cm}^{-3}\right)$ & 0.0451 & 0.201 & 0.610 & 0.709 & 1.57 & 2.34 & 0.420 \\
$R_{\text {eff }}(\mu \mathrm{m})$ & 0.105 & 0.155 & 0.191 & 0.192 & 0.232 & 0.437 & 0.024 \\
RH $(\%)$ & 28.2 & 51.7 & 85.5 & 81.6 & 98.9 & 100 & 15.7 \\
\hline
\end{tabular}

* $\mathrm{N}_{100}$ represents the number concentration of particles larger than $100 \mathrm{~nm}$

As noted above, extremely low visibility could occur at high humidity even if the aerosol volume concentration may be quite low. To confirm this assumption, sensitivity tests on correlations between visibility, $\mathrm{RH}$ and aerosol volume concentration are conducted in Sect. 4.3.

The aerosol volume concentration has been chosen for sensitivity tests. The volume concentration is representative of the aerosol pollution as it affects visibility and is much more easily measured compared to the aerosol number or surface concentration. The volume concentration is closely related to the mass concentration and can be derived from the mass concentration divided by an average particle density of $1.7 \mathrm{~g} \mathrm{~cm}^{-3}$ (Wehner et al., 2008). In contrast to insufficient PNSD measurements, long-term measurements of aerosol mass concentration are common in China. Therefore, aerosol volume concentration is used in the parameterization scheme in Sect. 4.4.

\subsection{Comparison between measured $K_{\text {ex }}$ values and those calculated from ambient RH PNSDs}

A comparison study of $K_{\text {ex }}$ based on the Mie calculations and the field measurements is summarized in this section. Using the inferred mean size-resolved hygroscopic growth factors and dry PNSDs, the ambient RH PNSDs can be obtained according to the method stated in Sect. 3.1. The $K_{\text {ex }}$ of the ambient RH PNSDs is calculated by the Mie Model, while measured $K_{\text {ex }}$ is obtained from visibility measurements. A comparison between the measured $K_{\text {ex }}$ values and those calculated from ambient RH PNSDs has been made.

Figure 3 shows the comparison between calculated and measured $K_{\text {ex }}$. The majority of $K_{\mathrm{ex}}$ is clustered near the 1:1 line for $K_{\mathrm{ex}}<1000 \mathrm{Mm}^{-1}\left(\log \left(K_{\mathrm{ex}}\right)<3.0\right.$, where $\log$ corresponds to $\log _{10}$ ), without significant systematic deviations. Corresponding RHs are mostly below $90 \%$. For $K_{\text {ex }}$ $>1000 \mathrm{Mm}^{-1}$ (VIS $<3 \mathrm{~km}$ ), the dispersion of $K_{\mathrm{ex}}$ gradually increases, and most of corresponding RHs are higher than $90 \%$. This reveals that the aerosol hygroscopicity would greatly influence the variation of $K_{\mathrm{ex}}$ and result in large deviations. Generally, the $K_{\text {ex }}$ calculated from ambient RH PNSDs agree with the measured values, with a correlation coefficient higher than $0.9\left(R^{2}=0.870\right)$.

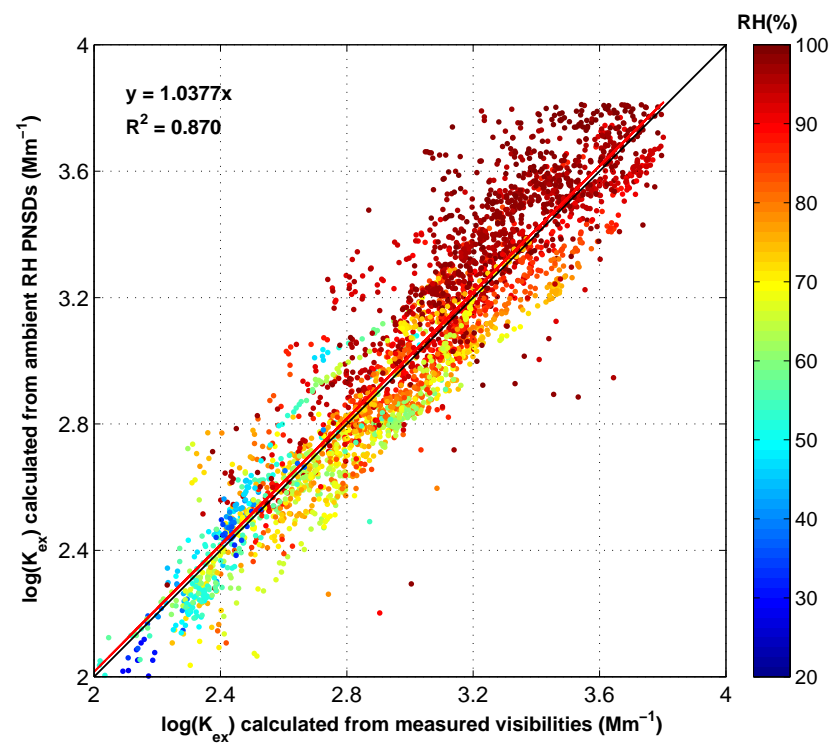

Fig. 3. Comparison of $K_{\mathrm{ex}}$ between calculated from ambient RH PNSDs and measured ones at log scale coordinates (log here corresponds to $\log _{10}$ ). Colored dots stand for the corresponding $\mathrm{RH}$.

The deviations in the comparison could come from two aspects. On the one hand, the visibility meter used for the in situ measurement of $K_{\mathrm{ex}}$ has uncertainties. Due to the possible influence of the forward scattering angle, particle size, source wavelength and site climatology, the systematic error of the visibility sensor is reported to be larger than $10 \%$ (Crosby, 2003). On the other hand, $K_{\text {ex }}$ calculated from ambient RH PNSDs also bear uncertainties. Size-resolved hygroscopic growth factors vary with time, using the mean growth factors would cause certain deviation, the mean level of which is estimated as no higher than $10 \%$. Another important factor is the RH, which is also closely related to the aerosol hygroscopic growth factors. Tests reveal that the sensitivity of $K_{\text {ex }}$ to RH variation is very high. That is, if increasing RH by $1 \%(\Delta \mathrm{RH}=1 \%)$ at a specific $\mathrm{RH}$, the corresponding growth rates of $K_{\mathrm{ex}}\left(\Delta K_{\mathrm{ex}}\right)$ by using a fixed PNSD in the Mie Model can be of great variation. At RH $<90 \%$, the $\Delta K_{\text {ex }}$ is within $10 \%$; while at RH $>90 \%$, the $\Delta K_{\mathrm{ex}}$ increases sharply. When 
RH grows above $95 \%$, the $\Delta K_{\text {ex }}$ would even exceed $20 \%$. It indicates that RH itself is of large uncertainty, and a tiny variation of RH can largely influence the value of $K_{\text {ex }}$, especially at $\mathrm{RH}>90 \%$. Therefore, ensuring the accuracy of the measured RH, particularly under high RH conditions, is very critical for both field campaigns and numerical simulations. Additionally, the mixing state of black carbon can induce uncertainty to the size-resolved refractive indices and result in the deviation of $K_{\mathrm{ex}}$ calculation. The standard deviations of the PNSD measurements in both particle size and number concentration (Wex et al., 2002; Wiedensohler et al., 2012) also contribute to the uncertainties of the calculated $K_{\text {ex }}$. The overall uncertainty of the calculation with the Mie Model is estimated as $34 \%$.

Briefly, due to the standard deviations derived from the visibility, RH and PNSD measurements, combined with the uncertainties of the $K_{\text {ex }}$ calculation induced by the sizeresolved hygroscopic growth factors and the mixing state of black carbon, discrepancies between the $K_{\text {ex }}$ calculated from ambient RH PNSDs and the measured values are inevitable. The results of the comparison are confirmed to be of acceptable range. The results also prove the reliability of our insitu observations, including the inferred size-resolved hygroscopic growth factors. They also confirm that it is appropriate to apply the inferred size-resolved hygroscopic growth factors in the Mie Model for the theoretical calculation of $K_{\text {ex }}$ in this paper.

\subsection{Dependence of $K_{\mathrm{ex}}$ on RH, volume concentration and PNSD patterns}

\subsubsection{Dependence of $K_{\mathrm{ex}}$ on $\mathrm{RH}$ and aerosol volume concentration}

Visibility can be converted from $K_{\mathrm{ex}}$ according to the User's Guide of the Visibility Meter (Eq. 2), thus $K_{\text {ex }}$ is taken as the proxy for visibility. Taking aerosol hygroscopic growth into consideration, $K_{\mathrm{ex}}$ at given $\mathrm{RH}$ and aerosol volume concentrations was calculated with the Mie Model using the average PNSD. Consequently, correlations between $K_{\text {ex }}$ (in log scale), RH and aerosol volume concentration are presented as is shown in Fig. 4b. The frequency distributions of aerosol volume concentration and $\mathrm{RH}$ are also displayed in Fig. 4a and $\mathrm{c}$.

In Fig. 4b, it should be noted that $K_{\text {ex }}$ generally increases with volume concentration, with the corresponding colors transforming from lower values (dark blue) to higher values (yellow). At $\mathrm{RH}<80 \%, K_{\mathrm{ex}}$ is more sensitive to the variation of aerosol volume concentration rather than to the increase of RH. This reveals the predominant influence of aerosol loading on visibility degradation at relatively low $\mathrm{RH}$ (RH $<80 \%$ ). At RH above $80 \%, K_{\mathrm{ex}}$ increases more sharply with RH than with the aerosol volume concentration. Under very humid conditions of $\mathrm{RH}>90 \%$, the dominant role of

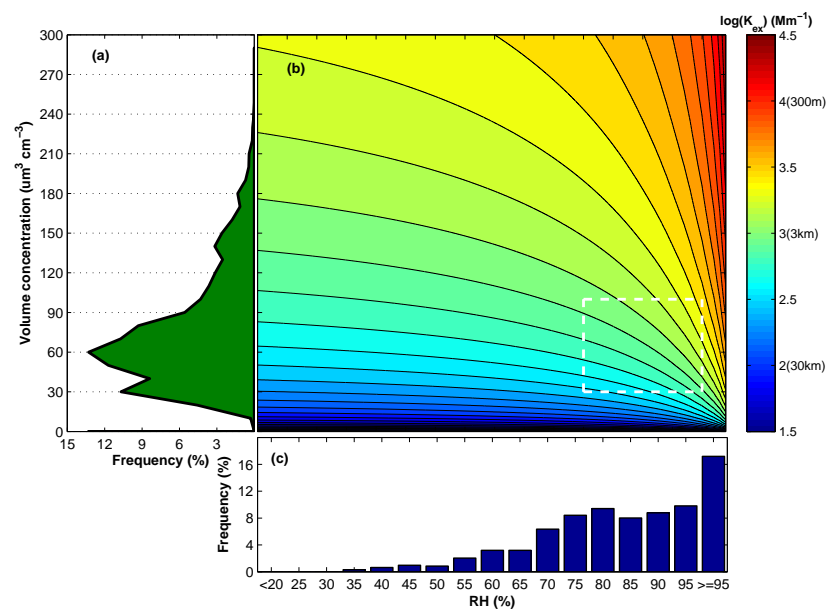

Fig. 4. (b) Calculated $K_{\mathrm{ex}}$ at given aerosol volume concentrations and $\mathrm{RH}$ at logarithmic scale; the crossed aera in white dashed line box represents the most common aerosol pollution and humidity state with the largest frequency distributions of aerosol volume concentration and RH; (a) and (c) Frequency distributions of measured aerosol volume concentrations and $\mathrm{RH}$, respectively.

aerosol hygroscopic growth in visibility impairment at high $\mathrm{RH}$ is even more evident.

Figure 4a shows the frequency distribution of measured aerosol volume concentrations. About $80 \%$ of the aerosol volume concentrations are less than $100 \mu \mathrm{m}^{3} \mathrm{~cm}^{-3}$. The aerosol volume concentration with the largest frequency $(13 \%)$ is about $55 \sim 65 \mu^{3} \mathrm{~cm}^{-3}$, far below the observed 95th percentile value $\left(157 \mu \mathrm{m}^{3} \mathrm{~cm}^{-3}\right)$. The aerosol volume concentrations barely reached over $200 \mu^{3} \mathrm{~cm}^{-3}$ in the insitu observations. Nonetheless, the high volume concentrations over $200 \mu \mathrm{m}^{3} \mathrm{~cm}^{-3}$ may still occur under certain weather conditions such as a calm and stable high pressure system. The occurrence frequency of high aerosol volume concentration events depends on synoptic conditions.

In contrast to the low frequency of high aerosol volume concentrations, the frequency distribution of $\mathrm{RH}$ seems to be more uniformly distributed at higher $\mathrm{RH}$ ranges as is shown in Fig. 4c. Generally, the occurrence probability of RH gradually increases with RH. The large frequency (over $35 \%$ ) of $\mathrm{RH}>85 \%$ demonstrates that high RH conditions frequently occurred during this summer campaign.

The area located in white dashed line box in Fig. 4b with the largest occurrence frequencies of aerosol volume concentration and RH represents the most common aerosol pollution and humidity state in the NCP. Low visibilities under such conditions rarely fall below $1 \mathrm{~km}$, which agrees well with the field observations, in which the low visibility range shows the highest occurrence frequency at $1 \sim 3 \mathrm{~km}$. Visibilities in that range are determined by the combined influence of aerosol volume concentration and aerosol hygroscopic growth. When extremely low visibility events (VIS $<1 \mathrm{~km}$, corresponding to $\log \left(K_{\mathrm{ex}}\right) \geq 3.5$ ) occur, there is 
either high aerosol volume concentration or high RH. Should VIS $<1 \mathrm{~km}$ occur under RH below $80 \%$, the corresponding aerosol volume concentrations would have to be higher than $200 \mu \mathrm{m}^{3} \mathrm{~cm}^{-3}$. However, it is evident that the aerosol volume concentrations rarely exceed $200 \mu \mathrm{m}^{3} \mathrm{~cm}^{-3}$ (with a probability below $2 \%$ ). Thus, extremely low visibility can hardly occur at low RH. On the other hand, should VIS $<1 \mathrm{~km}$ occur at aerosol volume concentrations below $100 \mu \mathrm{m}^{3} \mathrm{~cm}^{-3}$, the corresponding RH would have to be above $95 \%$. The occurrence probability of $\mathrm{RH}>95 \%$ is higher than $16 \%$, which indicates the high RH should be the predominant factor leading to extremely low visibilities at the average aerosol pollution level (as defined in Sect. 4.1).

This is in accordance with Zhang's (2010) result, which suggests that most of the low visibility days (VIS $<10 \mathrm{~km}$ ) in Beijing during summer (from 2003 to 2007) were caused by high RH. It also agrees with the previous result of Cheng's study on aerosol optical properties at Xinken in Pearl River Delta, China (Cheng et al., 2008a). They revealed that the water taken up by hygroscopic particles can contribute up to $50 \sim 60 \%$ of the $K_{\text {ex }}$ at $90 \% \mathrm{RH}$, suggesting that high RH plays a very important role in visibility degradation. However, it is slightly different from the conclusion in Yuan's study (Yuan et al., 2006), which stated that the effect of RH on visibility change was the smallest in comparation with that of $\left(\mathrm{NH}_{4}\right)_{2} \mathrm{SO}_{4}, \mathrm{NH}_{4} \mathrm{NO}_{3}$ and the remaining amount of $\mathrm{PM}_{2.5}$ in the metropolitan Kaohsiung. Sulfates in $\mathrm{PM}_{2.5}$ were reported to be the dominating parameter influencing light scattering. Nevertheless, the effect of sulphates on light extinction can be ascribed to the combined influence of their high number concentration and strong hygroscopic growth. In this sense, the conclusions in Yuan's study are in support of our work.

In general, at RH below $90 \%$, the influence of aerosol volume concentration on $K_{\mathrm{ex}}$ dominates. While at RH above $90 \%$, RH becomes the predominant factor controlling $K_{\mathrm{ex}}$. In most cases, visibility degradation is caused by the concurrence of aerosol pollution and hygroscopic growth at high RH.

\subsubsection{Dependence of $K_{\mathrm{ex}}$ on RH and PNSD patterns}

Results in Sect. 4.3.1 were derived from an averaged PNSD. In real-time observations, PNSDs are of temporal and spatial variations. The same aerosol volume concentration may correspond to different PNSD patterns. To test the sensitivity of $K_{\text {ex }}$ to the PNSD patterns, the concept of aerosol volume extinction coefficient $\left(K_{\text {ex-vol }}\right)$ is introduced, which refers to the $K_{\text {ex }}$ per unit aerosol volume concentration. In this way, the influence of aerosol volume concentration can be excluded. The variation of $K_{\text {ex-vol }}$ reflects the influence of PNSD patterns on aerosol light extinction at varying $\mathrm{RH}$.

Taking into consideration aerosol hygroscopic growth at subsaturated conditions in the Mie Model, the $K_{\text {ex-vol }}$ of all the measured PNSDs at each RH were obtained (Fig. 5). The

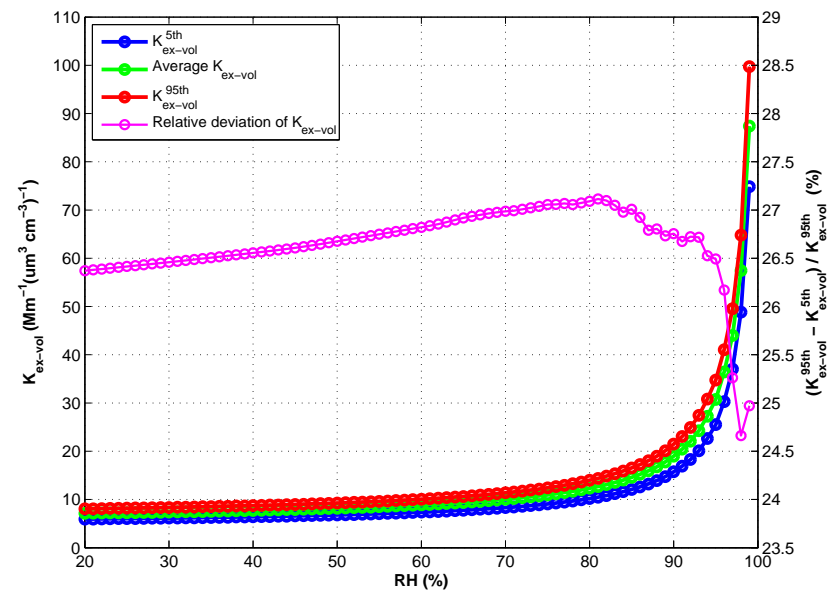

Fig. 5. Variation of the aerosol volume extinction coefficients $\left(K_{\text {ex-vol }}\right)$ with RH. Green, blue and red circled lines stand for the average, the 5 th and the 95 th percentiles of the volume extinction coefficients $\left(K_{\mathrm{ex}-\mathrm{vol}}^{5 \text { th }}\right.$ and $\left.K_{\mathrm{ex} \text {-vol }}^{95}\right)$. The magenta line represents the relative deviations of $K_{\text {ex-vol }}$, which is defined as $\left(K_{\text {ex-vol }}^{95 \text { th }}-\right.$ $\left.K_{\text {ex-vol }}^{5 \text { th }}\right) / K_{\text {ex-vol }}^{95 \text { th }}$.

green, blue and red circled lines respectively represent the average, the 5 th and 95 th percentile of $K_{\text {ex-vol }}\left(K_{\text {ex-vol }}^{5 \text { th }}\right.$ and $\left.K_{\mathrm{ex}-\mathrm{vol}}^{95}\right)$ under corresponding $\mathrm{RH}$. The magenta line represents the relative deviation of $K_{\mathrm{ex}-\mathrm{vol}}$ defined as $\left(K_{\mathrm{ex}-\mathrm{vol}}^{95}-\right.$ $\left.K_{\mathrm{ex}-\mathrm{vol}}^{5 \text { th }}\right) / K_{\mathrm{ex}-\mathrm{vol}}^{95}$. The relative deviation is representative of the influence of the PNSD patterns on $K_{\text {ex }}$.

Notably, an exponential correlation exists between the $K_{\text {ex-vol }}$ and RH. All three lines of $K_{\text {ex-vol }}$ increase slowly with $\mathrm{RH}$ at relatively low $\mathrm{RH}(\mathrm{RH}<80 \%), K_{\text {ex-vol varies }}$ between 5 and $15 \mathrm{Mm}^{-1}\left(\mu \mathrm{m}^{3} \mathrm{~cm}^{-3}\right)^{-1}$. The relative deviation at low RH also increases slowly but nearly keeps steady near $26.5 \%$. This indicates that the weak hygroscopic growth at low RH can hardly affect the $K_{\text {ex-vol }}$. The variation of the relative deviation is smaller than $1 \%$. PNSD patterns have little influence on $K_{\text {ex-vol }}$ at low RH. At RH $>90 \%$, the absolute deviations of $K_{\text {ex-vol }}\left(\left|K_{\text {ex-vol }}^{95 \text { th }}-K_{\text {ex-vol }}^{5 \text { th }}\right|\right)$ increases sharply with RH. The $K_{\mathrm{ex}-\mathrm{vol}}^{5 \text { th }}$ and $K_{\mathrm{ex} \text {-vol }}^{95 \text { th }}$ are larger than $25 \mathrm{Mm}^{-1}\left(\mu \mathrm{m}^{3} \mathrm{~cm}^{-3}\right)^{-1}$ at $95 \% \mathrm{RH}$, and they both exceed $75 \mathrm{Mm}^{-1}\left(\mu \mathrm{m}^{3} \mathrm{~cm}^{-3}\right)^{-1}$ at $99 \% \mathrm{RH}$. The hygroscopic growth at high RH greatly increases the light extinction by shifting the peaks of PNSDs to larger size bins, which have higher extinction efficiencies. Consequently, the PNSD patterns can affect the absolute deviations of $K_{\text {ex-vol }}$ at high RH. However, the relative deviation gradually reduced by $2.5 \%$ with RH growing from $80 \%$ to $99 \%$. The absolute deviations of $K_{\text {ex-vol }}$ caused by PNSD patterns vary with RH.

The absolute deviations of $K_{\text {ex-vol }}$ caused by PNSD patterns can theoretically be attributed to the mass or volume fractions of particles with different sizes, the optical properties of which differ from each other. Hence, the parameter coarse to fine volume ratio $\left(f_{\mathrm{c} / \mathrm{f}}\right)$ is introduced to describe the 

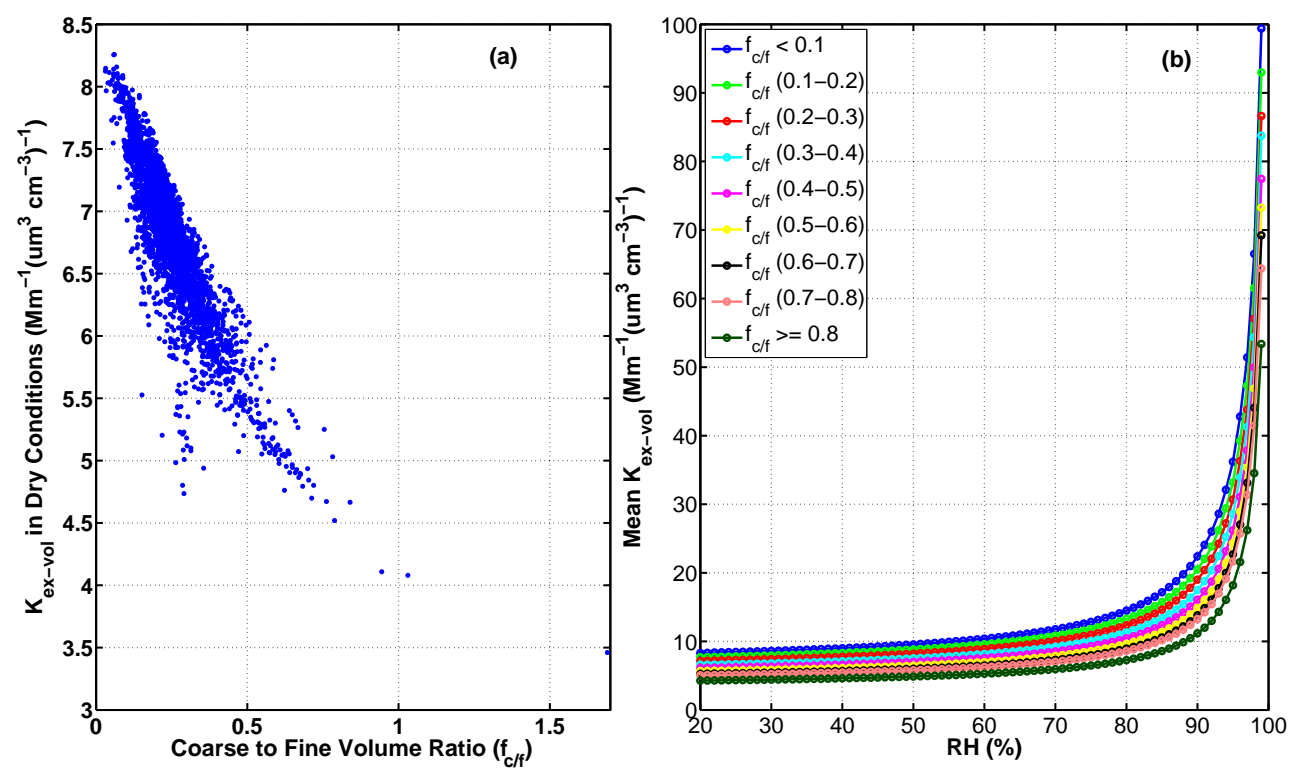

Fig. 6. Variation of the aerosol volume extinction coefficients $\left(K_{\text {ex-vol }}\right)$ with coarse to fine volume ratio $\left(f_{\mathrm{c} / \mathrm{f}}\right)$ in (a) dry conditions and (b) varying RH conditions, respectively. Colored lines in (b) stand for the corresponding coarse to fine volume ratio ranges as the legend shows.

variation of PNSD patterns. With the abundant aerosol mass concentration measurements in China, the volume ratios of coarse to fine particles can also be easily calculated from aerosol mass concentrations of $\mathrm{PM}_{1}, \mathrm{PM}_{2.5}$ and $\mathrm{PM}_{10}$ with a presumed aerosol density. In this study, $1 \mu \mathrm{m}$ is taken as the critical diameter differentiating between fine and coarse particles. The coarse particles refer to those in the range of $1 \sim 10 \mu \mathrm{m}\left(\mathrm{PM}_{1-10}\right)$, while fine particles are submicron particles $\left(\mathrm{PM}_{1}\right)$. For each PNSD, the volume concentrations of $\mathrm{PM}_{1-10}$ and $\mathrm{PM}_{1}$ are respectively calculated according to the corresponding size bins. The $f_{\mathrm{c} / \mathrm{f}}$ of the PNSD can thus be derived from the calculated volume concentrations of coarse and fine particles. Results show that the $f_{\mathrm{c} / \mathrm{f}}$ of the in-situ observations ranges from $0.03 \sim 1.69$, with a mean value and one standard deviation of $0.25 \pm 0.11$.

To evaluate the influence of PNSD patterns, or rather that of $f_{\mathrm{c} / \mathrm{f}}$, on $K_{\mathrm{ex}-\mathrm{vol}}$ at varying $\mathrm{RH}$, the $f_{\mathrm{c} / \mathrm{f}}$ is divided into bins. Considering the sample size in different $f_{\mathrm{c} / \mathrm{f}}$ ranges, the $f_{\mathrm{c} / \mathrm{f}}$ is divided into 9 bins, with $f_{\mathrm{c} / \mathrm{f}} \geq 0.8$ as a single bin and $f_{\mathrm{c} / \mathrm{f}}$ from 0 to 0.8 being divided into even bins of 0.1 intervals. The variation of the mean $K_{\text {ex-vol }}$ corresponding to each $f_{\mathrm{c} / \mathrm{f}}$ bin at a specific RH is representative of the effect of $f_{\mathrm{c} / \mathrm{f}}$ on $K_{\text {ex-vol }}$ at the set RH. The variation of $K_{\text {ex-vol with } f_{\text {c/f }} \text { in both }}$ dry and varying RH conditions is presented in Fig. 6a-b.

There exists an obvious negative correlation between $K_{\text {ex-vol }}$ and $f_{\text {c/f }}$ in Fig. 6 . The $K_{\text {ex-vol }}$ decreases notably with increasing $f_{\mathrm{c} / \mathrm{f}}$ in both dry and specific RH conditions, indicating the light extinction per unit volume is largely contributed by fine particles rather than by coarse particles. Since the calculated $f_{\mathrm{c} / \mathrm{f}}$ suggests that the volume concentration of $\mathrm{PM}_{1}$ is comparable with that of $\mathrm{PM}_{1-10}$, the dominant role of fine particles in contributing to light extinction is confirmed. This is also in accordance with Yuan's study (Yuan et al., 2006), in which it is stated that visible lights are mainly scattered by fine particles, since scattering generally contributes to most part of extinction, which can also be supported by the measured high single scattering albedo in the NCP (Ma et al., 2011; Yan et al., 2008b). It can also be easily explained using the Mie theory. The aerosol extinction capacity of unit volume concentration is mainly determined by the extinction efficiency. The extinction efficiency is determined by particle size parameter, and it may reach to the maximum when the particle size and the wavelength of incident light are comparable. In the visible light range $(400 \sim 700 \mathrm{~nm})$, fine particles (especially those between $100 \mathrm{~nm}$ and $1 \mu \mathrm{m}$ ), other than coarse particles, are the major component of maximizing the extinction efficiency.

From Fig. 6b it can be noted that, under all RH, the $K_{\text {ex-vol }}$ decreases with increasing $f_{\text {c/f }}$. The absolute deviations of the mean $K_{\text {ex-vol }}$ under different $f_{\mathrm{c} / \mathrm{f}}$ are less than $5 \mathrm{Mm}^{-1}\left(\mu \mathrm{m}^{3} \mathrm{~cm}^{-3}\right)^{-1}$ for RH below $80 \%$. However, the differences gradually become more apparent with increasing $\mathrm{RH}$, as what has already been shown in Fig. 5. At higher RH, the mean $K_{\text {ex-vol grows faster with varying RHs. To a great }}$ extent, a higher hygroscopicity of fine particles at higher RH might be responsible. Those highly hygroscopic particles are mainly in the fine mode, which means, they would make an even larger contribution to the $K_{\text {ex-vol }}$ at lower $f_{\text {c/f }}$. This is also the main reason for the larger difference of $K_{\text {ex-vol }}$ with different $f_{\mathrm{c} / \mathrm{f}}$ ranges under higher $\mathrm{RH}$ conditions.

Last but not least, there certainly are some uncertainties in the analysis of $f_{\mathrm{c} / \mathrm{f}}$ impacts on $K_{\mathrm{ex}-\mathrm{vol}}$. One is the lack of 
sufficient $f_{\mathrm{c} / \mathrm{f}}$ and PNSDs samples to draw a general conclusion, since a fixed $f_{\mathrm{c} / \mathrm{f}}$ is theoretically applicable to various PNSD patterns. The other might be the narrow variation range of in-situ $f_{\mathrm{c} / f}$. Results given here might just be a general correlation between $f_{\mathrm{c} / \mathrm{f}}$ and $K_{\mathrm{ex} \text {-vol }}$ in the NCP.

Overall, the sensitivity studies show that PNSD patterns can slightly influence the $K_{\text {ex-vol }}$. The absolute deviations between $K_{\mathrm{ex}-\mathrm{vol}}^{95}$ and $K_{\mathrm{ex}-\mathrm{vol}}^{5 \text { th }}$ are dominated by RH. The influence of PNSD patterns on the $K_{\text {ex-vol }}$ can be attributed to the effect of varying $f_{\mathrm{c} / \mathrm{f}}$ on the $K_{\mathrm{ex}-\mathrm{vol}}$. Results generally show that the $K_{\text {ex-vol }}$ is negatively correlated with the $f_{\mathrm{c} / \mathrm{f}}$. The absolute difference of $K_{\text {ex-vol }}$ with respect to varying $f_{\mathrm{c} / \mathrm{f}}$ is determined by $\mathrm{RH}$. The measurements of aerosol hygroscopicity are not only critical to the accuracy of sizeresolved hygroscopic growth factors but also to the variation of extinction coefficients per unit aerosol volume concentration. Since PNSD patterns only have slight influences on $K_{\text {ex-vol }}$ and measured in-situ $f_{\mathrm{c} / \mathrm{f}}$ did no change so much during the campaign, it should be appropriate to use an average PNSD in the Mie Model to calculate $K_{\mathrm{ex}}$. With given aerosol volume concentration and RH, $K_{\text {ex }}$ can be estimated from Fig. $4 \mathrm{~b}$. However, the influence of the $f_{\mathrm{c} / \mathrm{f}}$ on light extinction should be considered if the PNSDs are of highly spatiotemporal variation. Parameterization of $K_{\text {ex }}$ under the two conditions will be described in the following section.

\subsection{A parameterization for $K_{\text {ex }}$ calculation}

In the previous sections, low visibility and its influencing factors are analyzed in the NCP. Statistics show that more than half of the visibility records are below $3 \mathrm{~km}$, and over $10 \%$ are extremely low visibilities of VIS $<1 \mathrm{~km}$. The low visibility events in the NCP are frequently encountered and mostly accompanied with haze due to the concurrence of heavy aerosol pollution and strong hygroscopic growth at high RH. To reduce the costs of low-visibility-related accidents and to reduce delays at airports, parameterization of low visibilities on hazy days is of practical importance.

\subsubsection{Parameterization based on two factors of $\mathrm{RH}$ and aerosol volume concentration}

Based on the sensitivity study in Sect. 4.3, a parameterization scheme for $K_{\text {ex }}$ is set up. In consideration of the influence of aerosol hygroscopic growth in humid condition on the light extinction, $\mathrm{RH}$ is chosen as one of the factors for the parameterization. Instead of PNSD, aerosol volume concentration is chosen as the other parameter, because it is obtainable from mass concentration measurements, which are more common than PNSD measurements. Both factors can be easily aquired, which makes the parameterization more practical.

According to the relationship between $K_{\text {ex }}$ and aerosol volume concentration and the empirically exponential correlation between $K_{\text {ex }}$ and RH (Kasten, 1969; Carrico et al.,
1998, 2000; Kotchenruther et al., 1999; Hegg et al., 2002; Randriamiarisoa et al., 2006; Eichler et al., 2008), the multiple regression scheme can be set up as follows:

$K_{\text {ex }}=k \times \mathrm{V}^{\mathrm{a}} \times(1-\mathrm{RH})^{-b \cdot \mathrm{RH}}$,

where the units of $K_{\mathrm{ex}}, \mathrm{V}$ and $\mathrm{RH}$ are $\mathrm{Mm}^{-1}, \mu \mathrm{m}^{3} \mathrm{~cm}^{-3}$ and $\%$, respectively. The parameter $k$ stands for the average $K_{\text {ex-vol}}$, with a unit of $\mathrm{Mm}^{-1}\left(\mu \mathrm{m}^{3} \mathrm{~cm}^{-3}\right)^{-1}$.

To simplify calculations, Eq.(12) can be converted into a logarithmic format:

$\log \left(K_{\mathrm{ex}}\right)=b 0+b 1 \times \log \mathrm{V}+b 2 \times(\mathrm{RH} \times \log (1-\mathrm{RH}))$

Apparently, $b 1$ and $b 2$ in the Eq. (13) are equal to the exponents of $a$ and $-b$ in the Eq. (12), while $k$ is equivalent to $10^{b 0}$.

3230 valid data records are taken account into the regression analysis, excluding 63 records during a fog period. An $F$-test was applied with a confidence level of $95 \%(\alpha=$ $0.05)$. Regression results show that most of the data input are within the confidence level. The coefficients in Eq.(12) and the coefficient of determination $R^{2}$ (Table 3 ) can be derived from the calculated regression coefficients [ $\left.\begin{array}{llll}b & b 1 & b 2\end{array}\right]$, after eliminating the records that fell outside the confidence range. To test the reliability, a comparison between the $K_{\text {ex }}$ calculated from the regression and that derived from in-situ measured visibilities is made in a log scale.

The regression coefficient $a$ (the exponent of the aerosol volume concentration) is less than $1.0(a=0.944)$, which indicates a nonlinear correlation between $K_{\text {ex }}$ and aerosol volume concentration, revealing the potential influence of PNSD patterns on $K_{\text {ex }}$. This also confirms the conclusion of Sect. 4.3.2.

Figure $7 \mathrm{a}$ shows the comparison between the regressed and the measured $K_{\mathrm{ex}}$, with the 1:1 line displayed in black and the linear fit line in red. The dispersion of $K_{\text {ex }}$ below $3000 \mathrm{Mm}^{-1}$ is low. A strong correlation exists between the $K_{\text {ex }}$ and the volume concentration at RH below $90 \%$. $K_{\text {ex }}$ higher than $3000 \mathrm{Mm}^{-1}$ are more scattered, with the corresponding RH mostly higher than $90 \%$. This indicates that aerosol hygroscopic growth at high RH can greatly influence the variation of $K_{\mathrm{ex}}$. Nevertheless, the values are all distributed within \pm 0.23 (in log units or a factor of 1.7 in linear terms) from the 1:1 line, with a linear fitting slope of 1.0. Obviously, $K_{\mathrm{ex}}$ measurements agree well with the calculated values, because they were also applied in the optimal fitting.

On the other hand, the regression equation shows certain deviations. The corresponding correlation coefficient of the comparison between $K_{\mathrm{ex}}$ calculated from regression and measured visibilities is 0.879 (Fig. 7a). It is slightly higher than that of the comparison results between ambient RH PNSD calculated $K_{\text {ex }}$ and measured values in Sect. 4.2 $\left(R^{2}=\right.$ 0.870 ). This deviation might have occured due to the different calculation processes. The $K_{\text {ex }}$ calculated from the regression is only influenced by the measured $\mathrm{RH}$ and aerosol 
Table 3. Summary of Regression coefficients for the two parameterization schemes at specific confidence levels; see Eqs. (12) and (14) of Sect. 4.4 for description.

\begin{tabular}{|c|c|c|c|c|c|}
\hline & $k$ & $a$ & $b$ & $c$ & $R^{2}$ \\
\hline \multicolumn{6}{|c|}{$95 \%$ confidence level $(\alpha=0.05)$} \\
\hline Scheme $A^{*}$ & $9.08^{*} 10^{\wedge}( \pm 0.030)$ & $0.944 \pm 0.0163$ & $0.475 \pm 0.0084$ & & 0.892 \\
\hline Scheme B** & $3.93 * 10^{\wedge}( \pm 0.0316)$ & $1.01 \pm 0.0142$ & $0.411 \pm 0.0076$ & $-0.468 \pm 0.024$ & 0.924 \\
\hline \multicolumn{6}{|c|}{$90 \%$ confidence level $(\alpha=0.1)$} \\
\hline Scheme $A^{*}$ & $9.00 * 10^{\wedge}( \pm 0.024)$ & $0.946 \pm 0.013$ & $0.477 \pm 0.0066$ & & 0.905 \\
\hline Scheme B** & $3.85^{*} 10^{\wedge}( \pm 0.0246)$ & $1.02 \pm 0.0112$ & $0.410 \pm 0.006$ & $-0.475 \pm 0.0188$ & 0.937 \\
\hline \multicolumn{6}{|c|}{$68.3 \%(1 \sigma)$ confidence level $(\alpha=0.317)$} \\
\hline Scheme A* & $10.0^{*} 10^{\wedge}( \pm 0.0121)$ & $0.913 \pm 0.0066$ & $0.485 \pm 0.0034$ & & 0.946 \\
\hline Scheme $\mathrm{B}^{* *}$ & $4.20 * 10^{\wedge}( \pm 0.0125)$ & $0.991 \pm 0.0058$ & $0.408 \pm 0.003$ & $-0.480 \pm 0.0093$ & 0.962 \\
\hline
\end{tabular}

* Scheme A refers to the 2-factor parameterization scheme, $K_{\mathrm{ex}}=k \times \mathrm{V}^{a} \times(1-\mathrm{RH})^{-b^{*} \mathrm{RH}}$; ${ }^{*}$ Scheme B stands for the 3-factor parameterization scheme, $K_{\mathrm{ex}}=k \times \mathrm{V}^{a} \times(1-R H)^{-b * R H} \times f_{\mathrm{c} / \mathrm{f}}^{\mathrm{c}}$.

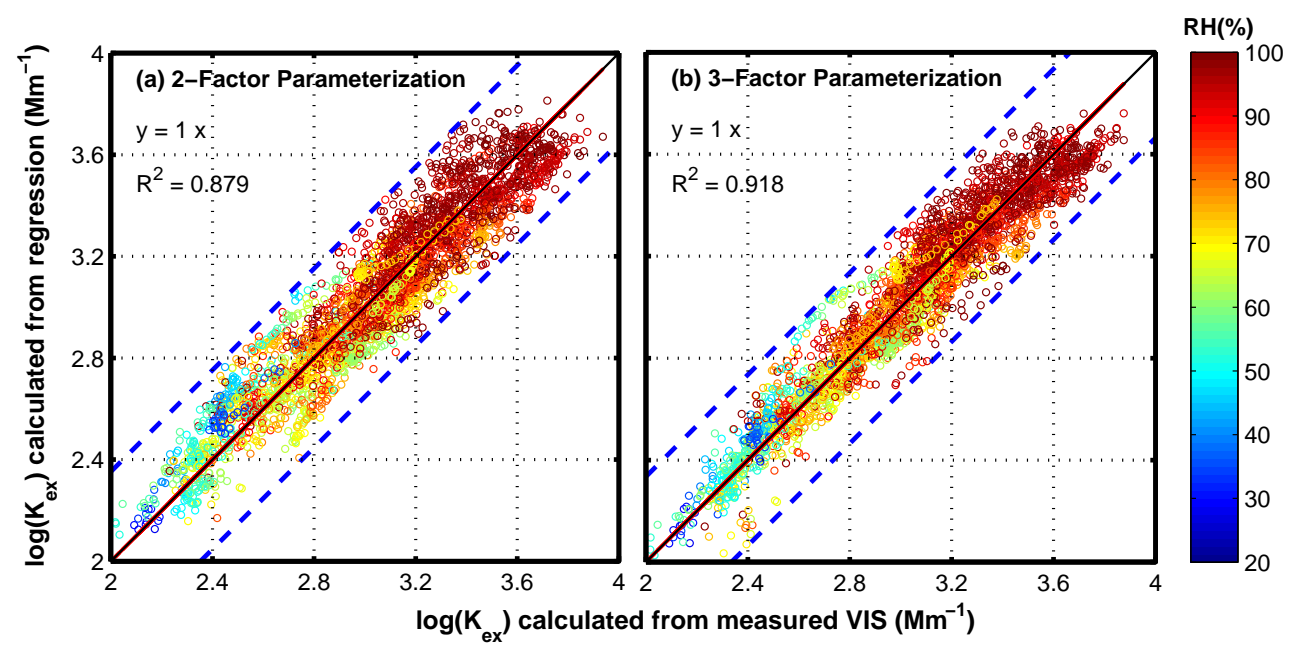

Fig. 7. Comparison results of ten-minute average $K_{\mathrm{ex}}$ between calculated from regression equations and measured visibilities, with (a) 2factor parameterization and (b) 3-factor parameterization (both at $95 \%$ confidence level); the colored circles stand for the corresponding RHs, which increase with color from blue to red.

volume concentration. However, uncertainties of the average size-resolved hygroscopic growth factors, refractive indices, RH and PNSD measurements (both particle size and number concentration) all contribute to the deviations of the $K_{\mathrm{ex}}$ calculated from ambient RH PNSDs.

Generally, the good agreement between the $K_{\text {ex }}$ calculated from the regression equation and that derived from measured visibilities confirms that the parameterization of $K_{\mathrm{ex}}$ with $\mathrm{RH}$ and aerosol volume concentration is reliable.

Similar studies on the correlations of visibility with chemical composition, $\mathrm{PM}_{2.5}$ mass concentration and $\mathrm{RH}$ have been done in Kaohsiung (Yuan et al., 2006). An empirical regression model of visibility as a function of $\left(\mathrm{NH}_{4}\right)_{2} \mathrm{SO}_{4}$, $\mathrm{NH}_{4} \mathrm{NO}_{3}$, the remaining amount of $\mathrm{PM}_{2.5}$ and $\mathrm{RH}$ was constructed. Results showed that there was a negative correlation between the visibility and all of the four regression parameters. They also concluded that RH was the only meteorological parameter that had effects on visibility. Generally, the aforementioned conclusions are in support of our work.

\subsubsection{Parameterization based on three factors of $\mathrm{RH}$, aerosol volume concentration and coarse to fine volume ratio}

As mentioned in Sect. 4.3.2, the influence of PNSD patterns on light extinction needs to be taken into account if the local aerosol mass or volume proportions of different size particles are of highly spatio-temporal variation.

Considering the impact of the coarse to fine volume ratio on light extinction, a 3-factor parameterization scheme was developed based on data at hand. Similarly, it can be fitted 
into the following format:

$K_{\mathrm{ex}}=k \times \mathrm{V}^{a} \times(1-\mathrm{RH})^{-b \cdot \mathrm{RH}} \times f_{\mathrm{clf}}^{c}$,

Where, the newly introduced parameter $f_{\mathrm{c} / \mathrm{f}}$ is the coarse to fine volume ratio, as defined in Sect. 4.3. The other parameters are of the same as those in Eq. (12).

Using the same processing method, regressions of the above two parameterization schemes at confidence levels of $1 \sigma, 90 \%$ and $95 \%$ were conducted, respectively. Regression results are also given in Table 3, which presents the coefficient of determination $R^{2}$ and the regression parameters $(a$, $b$ and $c$ ) with their corresponding variation ranges.

Evidently, the regression effect of the 3-factor parameterization scheme is improved at each specific confidence level. The corresponding coefficient of determination $R^{2}$ at confidence level of $95 \%$ is 0.924 , about 0.03 higher than that $\left(R^{2}=0.892\right)$ of the 2 -factor parameterization scheme. This reveals that the introduced parameter $f_{\mathrm{c} / \mathrm{f}}$ can effectively lower the uncertainty of PNSD patterns, thus increase the accuracy of the parameterization scheme for $K_{\mathrm{ex}}$ calculation.

In all, both parameterization schemes are of high reliability. This can be demonstrated by the good agreements between the $K_{\text {ex }}$ calculated from the two regression equations and measured visibilities in Fig. 7. Taking advantage of the widespread measurements of aerosol mass concentration in China, the aerosol volume concentration, as well as the mass or volume ratio of coarse to fine particles, can be easily used to predict these low visibility events. Furthermore, the hygroscopic growth factors of more hygroscopic particles were reported to be relatively constant at high RH conditions during the HaChi summer campaign (Liu et al., 2011), which makes the parameterization schemes widely applicable. Nevertheless, the parameterization developed is not applicable to the cases when dust events occur, since the optical and hygroscopic properties of dust might be quite different (Carrico, et al., 2003; Sano et al., 2003).

\section{Summary and conclusions}

Most of the low visibility conditions (VIS $<10 \mathrm{~km}$ ) in the NCP are accompanied with haze due to the concurrence of high aerosol loading and strong hygroscopic growth at high relative humidity (RH). To truly achieve reduced costs of low-visibility-related accidents and to increase the efficiency of transportation, a short-term local to regional scale forecast of visibility based on the proposed parameterization along with routine meteorological forecasts would be required. Understanding the controlling factors of low visibility in the NCP is critical to develop a parameterization of low-visibility conditions. Based on the in-situ measured visibility, relative humidity, particle number size distribution (PNSD) and sizeresolved hygroscopic growth factors during the HaChi summer campaign, the sensitivity of visibility to $\mathrm{RH}$, aerosol volume concentration and PNSD patterns is studied with the
Mie Model. A parameterization of low visibilities under hazy conditions is also proposed.

Field observations report that the average aerosol number (of particles larger than $100 \mathrm{~nm}$ ) and volume concentrations exceed $5300 \mathrm{~cm}^{-3}$ and $70 \mu^{3} \mathrm{~cm}^{-3}$, respectively. The effective radii are mainly distributed in the range of $105 \sim 437 \mathrm{~nm}$, with a mean value of $192 \mathrm{~nm}$. In-situ measured size-resolved hygroscopic growth factors of particles ranging from $50 \mathrm{~nm} \sim 1 \mu \mathrm{m}$ are higher than those of the other particle sizes. Deviations of hygroscopic growth factors for different particle size are larger when RH level is higher. At $99 \%$ $\mathrm{RH}$, the hygroscopic growth factors of particles larger than $30 \mathrm{~nm}$ are all higher than 2.0, and those of particles ranging from $200 \mathrm{~nm} \sim 1 \mu \mathrm{m}$ even exceed 3.0, suggesting strong aerosol hygroscopic growth in the NCP. During the summer campaign, about $90 \%$ of the visibility records are below $10 \mathrm{~km}$, and over half of the visibility records are lower than $3 \mathrm{~km}$. Over $90 \%$ of the visibility data are below $5 \mathrm{~km}$, when the aerosol volume concentrations exceeds $75 \mu \mathrm{m}^{3} \mathrm{~cm}^{-3}$ or when $\mathrm{RH}>90 \%$. These results indicate that the low visibility events are of high frequency in the NCP.

The observational data and measured size-resolved hygroscopic growth factors have been confirmed to be reliable by the good agreement between the extinction coefficients $\left(K_{\text {ex }}\right)$ calculated from ambient RH PNSDs and that derived from measured visibilities. The differences existing in the comparisons can be attributed to the possible uncertainties in the measurements of visibility, $\mathrm{RH}$ and PNSDs, as well as the deviations of the $K_{\text {ex }}$ calculation with the Mie Model.

Low visibility events can easily occur due to the high aerosol loading and strong hygroscopic growth in the NCP. Sensitivity studies show that the aerosol volume concentration determines the variation of $K_{\mathrm{ex}}$ at $<90 \%$. The relative humidity becomes the dominant influencing factor of $K_{\mathrm{ex}}$ at $\mathrm{RH}>90 \%$. In most cases, visibility degradation is caused by the concurrence of aerosol pollution and aerosol hygroscopic growth at high relative humidity. In-situ observations reveal that aerosol volume concentrations above $200 \mu^{3} \mathrm{~cm}^{-3}$ are scarce. Extremely low visibilities (VIS $<1 \mathrm{~km}$ ) can also happen at low aerosol volume concentration, which reveals the crucial influence of aerosol hygroscopic growth on visibility impairment.

The sensitivity of $K_{\text {ex }}$ to PNSD patterns is tested by introducing the concept of extinction coefficient per unit aerosol volume concentration $\left(K_{\mathrm{ex}-\mathrm{vol}}\right)$. Results show that the PNSD pattern has little influence on the $K_{\text {ex-vol }}$ at low relative humidity ( $\mathrm{RH}<80 \%$ ). The variation of the relative deviation between the 95th and the 5th $K_{\text {ex-vol }}$ is below $1 \%$. At RH $>80 \%$, PNSD patterns may slightly influence the $K_{\text {ex-vol }}$, with a largest relative deviation of $2.5 \%$. The effect of PNSD patterns on $K_{\text {ex-vol }}$ can be theoretically attributed to the impacts of varying coarse to fine volume ratio $\left(f_{\mathrm{c} / f}\right)$ on $K_{\text {ex-vol }}$. The $K_{\text {ex-vol }}$ decreases remarkably with the increase of $f_{\text {clf }}$, and the absolute difference of $K_{\text {ex-vol }}$ with respect to varying $f_{\mathrm{c} / \mathrm{f}}$ is determined by $\mathrm{RH}$. Under the condition of highly 
spatio-temporal varied PNSDs, the influence of the $f_{\mathrm{c} / \mathrm{f}}$ on light extinction needs to be taken into consideration.

The relative humidity can influence aerosol optical properties, as the size-resolved hygroscopic growth factor of ambient aerosols is closely related to the relative humidity. The measurements of aerosol mass concentration have been conducted all over China for many years. The aerosol volume concentration, along with the mass or volume ratio of coarse to fine particles, can be easily derived from the measured aerosol mass concentrations, which can be applied combined with RH measurements in the prediction of low visibilities. Both of the two- and three-factor parameterization schemes of low visibilities are confirmed to be reliable $\left(R^{2}=0.892\right.$ and 0.924 at $95 \%$ confidence level, respectively), with good agreements between the $K_{\text {ex }}$ calculated from the regression equations and the measured values.

Acknowledgements. This work is supported by the China 973 Program 2011CB403402, the National Natural Science Foundation of China (NSFC) under Grant No. 40875001, 40975083, and the German Science Foundation under grant DFG WI1449/14-1. The Basic Research Fund of Chinese Academy of Meteorological Sciences (2008Z011) also partially supported this work on visibility.

Edited by: V.-M. Kerminen

\section{References}

Ambient air quality standard of China (GB3095-2012) in Chinese (newly resived), available at: http://www.zhb.gov.cn/gkml/ hbb/bgth/201111/W020111121388004546031.pdf, last access: 23 February 2012.

Anderson, T. L., Charlson, R. J., Schwartz, S. E., Knutti, R., Boucher, O., Rodhe, H., and Heintzenberg, J.: Climate forcing by aerosols - a hazy picture, Science, 300, 1103-1104, 2003.

Andreae, M. O., Schmid, O., Yang, H., Chand, D., Yu, J. Z., Zeng, L. M., and Zhang, Y. H.: Optical properties and chemical composition of the atmospheric aerosol in urban Guangzhou, China, Atmos. Environ., 42, 6335-6350, 2008.

Bergin, M. H., Cass, G. R., Xu, J., Fang, C., Zeng, L. M., Yu, T., Salmon, L. G., Kiang, C. S., Tang, X. Y., Zhang, Y. H., and Chameides, W. L.: Aerosol radiative, physical, and chemical properties in Beijing during June 1999, J. Geophys. Res.-Atmos., 106, 17969-17980, 2001.

Birmili, W., Stratmann, F., and Wiedensohler, A.: Design of a DMA-based size spectrometer for a large particle size range and stable operation, J. Aerosol Sci., 30, 549-533, 1999.

Birmili, W., Wiedensohler, A., Heintzenberg, J., and Lehmann, K.: Atmospheric particle number size distribution in Central Europe: statistical relations to air masses and meteorology, J. Geophys. Res., 106, 32005-32018, 2001.

Bohren, C. F. and Huffman, D. R.: Absorption and Scattering of Light by Small Particles, John Wiley, Hoboken, 477-482, 1983.

Carrico, C. M., Bergin, M. H., Xu, J., Baumann, K., and Maring, H.: Urban aerosol radiative properties: measurements during the 1999 Atlanta Supersite Experiment, J. Geophys. Res., 108, D78422, doi:10.1029/2001JD001222, 2003.
Carrico, C. M., Kus, P., Rood, M. J., Quinn, P. K., and Bates, T. S.: Mixtures of pollution, dust, sea salt, and volcanic aerosol during ACE-Asia: Radiative properties as a function of relative humidity, J. Geophys. Res., 108, D238650, doi:10.1029/2003JD003405, 2003.

Carrico, C. M., Rood, M. J., and Ogren, J. A.: Aerosol light scattering properties at Cape Grim, Tasmania, during the First Aerosol Characterization Experiment (ACE 1), J. Geophys. Res., 103, 16565-16574, 1998.

Carrico, C. M., Rood, M. J., Ogren, J. A., Neusüss, C., Wiedensohler, A., and Heinzenberg, J.: Aerosol optical properties at Sagres Portugal, during ACE-2, Tellus 52B, 694-715, 2000.

Chang, D., Song, Y., and Liu, B.: Visibility trends in six megacities in China 1973-2007, Atmos. Res., 94, 161-167, 2009.

Cheng, Y. F., Eichler, H., Wiedensohler, A., Heintzenberg, J., Zhang, Y. H., Hu, M., Herrmann, H., Zeng, L. M., Liu, S., Gnauk, T., Brüggemann, E., and He, L. Y.: Mixing state of elemental carbon and non-light-absorbing aerosol components derived from in situ particle optical properties at Xinken in Pearl River Delta of China, J. Geophys. Res., 111, D20204, doi:10.1029/2005JD006929, 2006.

Cheng, Y. F., Wiedensohler, A., Eichler, H., Su, H., Gnauk, T., Brüggemann, E., Herrmann, H., Heintzenberg, J., Slanina, J., Tuch, T., Hu, M., and Zhang, Y. H.: Aerosol optical properties and related chemical apportionment at Xinken in Pearl River Delta of China, Atmos. Environ., 42, 6351-6372, 2008a.

Cheng, Y. F., Heintzenberg, J., Wehner, B., Wu, Z. J., Su, H., Hu, M., and Mao, J. T.: Traffic restrictions in Beijing during the Sino-African Summit 2006: aerosol size distribution and visibility compared to long-term in situ observations, Atmos. Chem. Phys., 8, 7583-7594, doi:10.5194/acp-8-7583-2008, 2008b.

Covert, D. S., Charlson, R. J., and Ahlquist, N. C.: A study of the relationship of chemical composition and humidity to light scattering by aerosols, J. Appl. Meteorol., 11, 968-976, 1972.

Crosby, J. D.: Visibility sensor accuracy: what's realistic? in: 12th Symposium on Meteorological Observations and Instrumentation, Long Beach, CA, 13 February 2003, 2003.

Deng, X., Tie, X., Wu, D., Zhou, X., Bi, X., Tan, H., Li, F., and Jiang, C.: Long-term trend of visibility and its characterizations in the Pearl River Delta (PRD) region, China, Atmos. Environ., 42, 1424-1435, 2008.

Deng, Z. Z., Zhao, C. S., Zhang, Q., Huang, M. Y., and Ma, X. C.: Statistical analysis of microphysical properties and the parameterization of effective radius of warm clouds in Beijing area, Atmos. Res., 93, 888-896, 2009.

Deng, Z. Z., Zhao, C. S., Ma, N., Liu, P. F., Ran, L., Xu, W. Y., Chen, J., Liang, Z., Liang, S., Huang, M. Y., Ma, X. C., Zhang, Q., Quan, J. N., Yan, P., Henning, S., Mildenberger, K., Sommerhage, E., Schäfer, M., Stratmann, F., and Wiedensohler, A.: Size-resolved and bulk activation properties of aerosols in the North China Plain, Atmos. Chem. Phys., 11, 3835-3846, doi:10.5194/acp-11-3835-2011, 2011.

Eichler, H., Cheng, Y. F., Birmili, W., Wiedensohler, A., Brüggemann, E., Gnauk, T., Herrmann, H., Althausen, D., Ansmann, A., Engelmann, R., Tesche, M., Zhang, Y. H., Hu, M., Liu, S., Zeng, L. M.: Hygroscopic properties and ambient extinction of aerosol particles in South-Eastern China, Atmos. Environ., 42, 6321-6334, doi:10.1016/j.atmosenv.2008.05.007, 2008. 
FD12P User Guide in English: available at: http://www.vaisala. com/Vaisala\%20Documents/User\%20Guides\%20and\% 20Quick\%20Ref\%20Guides/FD12P\%20User\%20Guide\% 20in\%20English.pdf, last access: 5 June 2012.

Griffing, G. W.: Relations between the prevailing visibility, nephelometer scattering coefficient and sunphotometer turbidity coefficient, Atmos. Environ., 14, 577-584, 1980.

Hegg, D. A., Covert, D. S., Crahan, K.: The dependence of aerosol light-scattering on RH over the Pacific Ocean. Geophys. Res. Lett., 29, 1219, doi:10.1029/2001GL014495, 2002.

Hennig, T., Massling, A., Brechtel, F. J., and Wiedensohler, A.: A tandem DMA for highly temperature-stabilized hygroscopic particle growth measurements between $90 \%$ and $98 \%$ relative humidity, J. Aerosol Sci., 36, 1210-1223, doi:10.1016/j.jaerosci.2005.01.005, 2005.

Hidy, G. M.: Surface-level fine particle mass concentrations: from hemispheric distributions to megacity sources, J. Air Waste Manage. Assoc., 59, 770-789, 2009.

Hoyle, C. R., Myhre, G., and Isaksen, I. S. A.: Present-day contribution of anthropogenic emissions from China to the global burden and radiative forcing of aerosol and ozone, Tellus B, 61, 618-624, 2009.

Husar, R. B., Husar, J. D., and Martin, L.: Distribution of continental surface aerosol extinction based on visual range data, Atmos. Environ., 34, 5067-5078, 2000.

Hussein, T., Dal Maso, M., Petäjä, T., Koponen, I. K., Paatero, P., Aalto, P. P., Hämeri, K., and Kulmala, M.: Evaluation of an automatic algorithm for fitting the particle number size distributions, Boreal Environ. Res., 10, 337-355, 2005.

Hyslop, N. P.: Impaired visibility: the air pollution people see, Atmos. Environ., 43, 182-195, 2009.

Johnson, J. C.: Physical Meteorology, 79-90, Cambridge, Mass., MIT Press, 1954.

Kasten, F.: Visibility forecast in the phase of pre-condensation, Tellus 21, 631-635, 1969.

Kotchenruther, R. A., Hobbs, P. V., and Hegg, D. A.: Humidification factors for atmospheric aerosols off the mid-Atlantic coast of the United States, J. Geophys. Res., 104, 2239-2251, 1999.

Lesins, G., Chylek, P., and Lohman, U.: A study of internal and external mixing scenarios and its effect on aerosol optical properties and direct radiative forcing. J. Geophys. Res., 107, 4094, doi:10.1029/2001JD000973, 2002.

Liu, P. F., Zhao, C. S., Göbel, T., Hallbauer, E., Nowak, A., Ran, L., Xu,W. Y., Deng, Z. Z., Ma, N., Mildenberger, K., Henning, S., Stratmann, F., and Wiedensohler, A.: Hygroscopic properties of aerosol particles at high relative humidity and their diurnal variations in the North China Plain, Atmos. Chem. Phys., 11, 3479-3494, doi:10.5194/acp-11-3479-2011, 2011.

Liu, P., Zhao, C., Zhang, Q., Deng, Z., Huang, M., Ma, X., and Tie, X.: Aircraft study of aerosol vertical distributions over Beijing and their optical properties, Tellus B, 61, 756-767, 2009.

Ma, N., Zhao, C. S., Müller, T., Cheng, Y. F., Liu, P. F., Deng, Z. Z., Xu, W. Y., Ran, L., Nekat, B., van Pinxteren, D., Gnauk, T., Müller, K., Herrmann, H., Yan, P., Zhou, X. J., and Wiedensohler, A.: A new method to determine the mixing state of light absorbing carbonaceous using the measured aerosol optical properties and number size distributions, Atmos. Chem. Phys., 12, 23812397, doi:10.5194/acp-12-2381-2012, 2012.
Ma, N., Zhao, C. S., Nowak, A., Müller, T., Pfeifer, S., Cheng, Y. F., Deng, Z.Z., Liu, P. F., Xu, W. Y., Ran, L., Yan, P., Göbel, T., Hallbauer, E., Mildenberger, K., Henning, S., Yu, J., Chen, L. L., Zhou, X. J., Stratmann, F., and Wiedensohler, A.: Aerosol optical properties in the North China Plain during HaChi campaign: an in-situ optical closure study, Atmos. Chem. Phys., 11, 59595973, doi:10.5194/acp-11-5959-2011, 2011.

Middleton, W. E. K.: Vision through the Atmosphere, University of Toronto Press, Toronto, Canada, 104-122, 1952.

Mie, G.: Beiträge zur optic trüber Medien speziell kolloidaler Metallösungen, Ann. Phys., 25, 377-445, 1908.

Motallebi, N. and Cahill, T. A.: Influence of particulate size on statistical studies of visibility at California regions, Atmosfera, 3, 111-126, 1990.

Nowak, A.: Das Feuchte Partikelgroessenspektrometer: Eine Neue Messmethode Zur Bestimmung Von Partikelgroessenverteilung $(<1 \mu \mathrm{m})$ und Groessenaufgeloesten Hygroskopischen Wachsumsfaktoren Bei Definierten Luftfeuchten, Ph.D. Thesis, Leibnitz Institute for Tropospheric Research, University of Leipzig, Germany, 2005.

Ouimette, J. R. and Flagan, R. C.: The extinction coefficient of multicomponent aerosols, Atmos. Environ., 16, 2405-2419, 1982.

Pan, X. L., Yan, P., Tang, J., Ma, J. Z., Wang, Z. F., Gbaguidi, A., and Sun, Y. L.: Observational study of influence of aerosol hygroscopic growth on scattering coefficient over rural area near Beijing mega-city, Atmos. Chem. Phys., 9, 7519-7530, doi:10.5194/acp-9-7519-2009, 2009.

Petters, M. D. and Kreidenweis, S. M.: A single parameter representation of hygroscopic growth and cloud condensation nucleus activity, Atmos. Chem. Phys., 7, 1961-1971, doi:10.5194/acp-71961-2007, 2007.

Quinn, P. K. and Bates, T.: North American, Asian, and Indian haze: similar regional impacts on climate?, Geophys. Res. Lett., 30, 1555, 2003.

Randles, C. A., Russell, L. M., and Ramaswamy, V.: Hygroscopic and optical properties of organic sea salt aerosol and consequences for climate forcing, Geophys. Res. Lett., 31, L16108, doi:10.1029/2004GL020628, 2004.

Randriamiarisoa, H., Chazette, P., Couvert, P., Sanak, J., and Mégie, G.,: Relative humidity impact on aerosol parameters in a Paris suburban area, Atmos. Chem. Phys., 6, 1389-1407, doi:10.5194/acp-6-1389-2006, 2006.

Sano, I., Mukai, S., Okada, Y., Holben, B. N., Ohta, s., and Takamura, T.: Optical properties of aerosols during APEX and ACE-Asia experiments, J. Geophys. Res., 108, D238649, doi:10.1029/2002JD003263, 2003.

Seinfeld, J. H. and Pandis, S. N.: Atmospheric Chemistry and Physics, John Wiley \& Sons, Inc., New York, USA, 1998.

Shen, Z. X., Cao, J. J., Tong, Z., Liu, S. X., Reddy, L. S. S., Han, Y. M., Zhang, T., and Zhou, J.,: Chemical Characteristics of Submicron Particles in Winter in Xi'an, Aerosol Air Qual. Res., 9, 80-93, 2009.

Sloane, C. S.: Optical properties of aerosols - comparison of measurements with model calculations, Atmos. Environ., 17, 409416, 1983.

Sloane, C. S.: Optical properties of aerosols of mixed composition, Atmos. Environ., 18, 871-878, 1984.

Sorooshian, A., Hersey, S., Brechtel, F. J., Corless, A., Flagan, R. C., and Seinfeld, J. H.: Rapid, size-resolved aerosol hygroscopic 
growth measurements: Differential Aerosol Sizing and Hygroscopicity Spectrometer Probe (DASH-SP), Aerosol Sci. Tech., 42, 445-464, 2008.

Stock, M., Cheng, Y. F., Birmili, W., Massling, A., Wehner, B., Müller, T., Leinert, S., Kalivitis, N., Mihalopoulos, N., and Wiedensohler, A.: Hygroscopic properties of atmospheric aerosol particles over the Eastern Mediterranean: implications for regional direct radiative forcing under clean and polluted conditions, Atmos. Chem. Phys., 11, 4251-4271, doi:10.5194/acp11-4251-2011, 2011.

Swietlicki, E., Hansson, H.-C., Hämeri, K., Svenningsson, B., Massling, A., McFiggans, G., McMurry, P. H., Petäjä, T., Tunved, P., Gysel, M., Topping, D., Weingartner, E., Baltensperger, U., Rissler, J., Wiedensohler, A., and Kulmala, M.: Hygroscopic properties of submicrometer atmospheric aerosol particles measured with H-TDMA instruments in various environments: a review, Tellus B, 60, 432-469, 2008.

Wang, P., Che, H. Z., Zhang, X. C., Song, Q. L., Wang, Y. Q., Zhang, Z. H., Dai, X., and Yu, D. J.: Aerosol optical properties of regional background atmosphere in Northeast China, Atmos. Environ., 44, 4404-4412, 2010.

Wauben, W.: Evaluation of the Vaisala FD12P 1.91S firmware with insect filtering, Technical report (TR-316), De Bilt, 2011. Available at: http://www.knmi.nl/knmi-library/knmipubTR/TR316. pdf, last access: 20 February 2012.

Wehner, B., Birmili, W., Ditas, F., Wu, Z., Hu, M., Liu, X., Mao, J., Sugimoto, N., and Wiedensohler, A.: Relationships between submicrometer particulate air pollution and air mass history in Beijing, China, 2004-2006, Atmos. Chem. Phys., 8, 6155-6168, doi:10.5194/acp-8-6155-2008, 2008.

Wen, C.-C. and Yeh, H.-H.: Comparative influences of airborne pollutants and meteorological parameters on atmospheric visibility and turbidity, Atmos. Res., 96, 496-509, 2010.

Wex, H.: Closure and sensitivity studies on physical parameters of rural continental aerosols, Ph. D. Thesis, Leipzig University, Leipzig, Germany, 2002.

Wex, H., Neusüß, C., Wendisch, M., Stratmann, F., Koziar, C., Keil, A., Wiedensohler, A., and Ebert, M.: Particle scattering, backscattering, and absorption coefficients: An in situ closure and sensitivity study, J. Geophys. Res., 107, 8122, doi:10.1029/2000JD000234, 2002.

Whitby, K. T.: The physical characteristics of sulfur aerosols, Atmos. Environ., 12, 135-159, 1978.

Wiedensohler, A., Birmili, W., Nowak, A., Sonntag, A., Weinhold, K., Merkel, M., Wehner, B., Tuch, T., Pfeifer, S., Fiebig, M., Fjäraa, A. M., Asmi, E., Sellegri, K., Depuy, R., Venzac, H., Villani, P., Laj, P., Aalto, P., Ogren, J. A., Swietlicki, E., Williams, P., Roldin, P., Quincey, P., Hüglin, C., Fierz-Schmidhauser, R., Gysel, M., Weingartner, E., Riccobono, F., Santos, S., Grüning, C., Faloon, K., Beddows, D., Harrison, R., Monahan, C., Jennings, S. G., O’Dowd, C. D., Marinoni, A., Horn, H.-G., Keck, L., Jiang, J., Scheckman, J., McMurry, P. H., Deng, Z., Zhao, C. S., Moerman, M., Henzing, B., de Leeuw, G., Löschau, G., and Bastian, S.: Mobility particle size spectrometers: harmonization of technical standards and data structure to facilitate high quality long-term observations of atmospheric particle number size distributions, Atmos. Meas. Tech., 5, 657-685, doi:10.5194/amt5-657-2012, 2012.
Wu, D., Tie, X., Li, C., Ying, Z., Kai-Hon Lau, A., Huang, J., Deng, X., and Bi, X.: An extremely low visibility event over the Guangzhou region: a case study, Atmos. Environ., 39, 65686577, 2005.

Xu, W. Y., Zhao, C. S., Ran, L., Deng, Z. Z., Liu, P. F., Ma, N., Lin, W. L., Xu, X. B., Yan, P., He, X., Yu, J., Liang, W. D., and Chen, L. L.: Characteristics of pollutants and their correlation to meteorological conditions at a suburban site in the North China Plain, Atmos. Chem. Phys., 11, 4353-4369, doi:10.5194/acp-114353-2011, 2011.

Yan, P., Pan, X. L., Tang, J., Tang, J., Zhou, X. J., and Zeng, L. M.: An experimental study on the influence of relative humidity on the atmospheric aerosol scattering coefficient at an urban site in Beijing, Acta Meteorol. Sin., 6, 11-119, 2008a.

Yan, P., Tang, J., Huang, J., Mao, J. T., Zhou, X. J., Liu, Q., Wang, Z. F., and Zhou, H. G.: The measurement of aerosol optical properties at a rural site in Northern China, Atmos. Chem. Phys., 8 , 2229-2242, doi:10.5194/acp-8-2229-2008, 2008b.

Yang, F., Tan, J., Zhao, Q., Du, Z., He, K., Ma, Y., Duan, F., Chen, G., and Zhao, Q.: Characteristics of $\mathrm{PM}_{2.5}$ speciation in representative megacities and across China, Atmos. Chem. Phys., 11, 5207-5219, doi:10.5194/acp-11-5207-2011, 2011.

Yu, H., Wu, C., Wu, D., and Yu, J. Z.: Size distributions of elemental carbon and its contribution to light extinction in urban and rural locations in the pearl river delta region, China, Atmos. Chem. Phys., 10, 5107-5119, doi:10.5194/acp-10-5107-2010, 2010.

Yuan, C.-S., Lee, C.-G., Liu, S.-H., Chang, J.-C., Yuan, C., and Yang, H.-Y.: Correlation of atmospheric visibility with chemical composition of Kaohsiung aerosols, Atmos. Res., 82, 663-679, 2006.

Zhang, Q. H., Zhang, J. P., and Xue, H. W.: The challenge of improving visibility in Beijing, Atmos. Chem. Phys., 10, 78217827, doi:10.5194/acp-10-7821-2010, 2010.

Zhao, C., Tie, X., Brasseur, G., Noone, K. J., Nakajima, T., Zhang, Q., Zhang, R., Huang, M., Duan, Y., Li, G., and Ishizaka, Y.: Aircraft measurements of cloud droplet spectral dispersion and implications for indirect aerosol radiative forcing, Geophys. Res. Lett., 33, L16809, doi:10.1029/2006g1026653, 2006a.

Zhao, C., Tie, X., and Lin, Y.: A possible positive feedback of reduction of precipitation and increase in aerosols over Eastern Central China, Geophys. Res. Lett., 33, L11814, doi:10.1029/2006gl025959, 2006b. 